\title{
Neutron analyses for nuclear materials: Texture, residual stresses and small angle scattering
}

\author{
Jean-Luc Béchade ${ }^{1, a}$, Marie Hélène Mathon ${ }^{2}$ and Yann de Carlan ${ }^{1}$ \\ ${ }^{1}$ CEA, DEN, Service de Recherches Métallurgiques Appliquées, 91191 Gif-sur-Yvette, France \\ ${ }^{2}$ CEA, LLB-Orphée, France
}

\begin{abstract}
Neutron techniques are very useful for metallurgical investigations of nuclear materials, bringing complementary results compared to others analysis techniques like XRD, TEM, APT. Especially, statistical information representative of the bulk material are obtained. Various nuclear materials examples are given here, on: texture analyses, residual stress determination and Small Angle Neutron Scattering before and after irradiation.
\end{abstract}

\section{Introduction}

Investigations of the microstructure of Nuclear Materials (actual GEN 2\&3 and future GEN 4 components) are needed, in strong relationship with physical and mechanical properties, especially after irradiation.

Texture and residual stresses are formed during the fabrication process and they have a strong impact on the behaviour for in service and accidental conditions. The full microstructure and especially the precipitates have to be analysed. For nanostructured materials, strong effect on mechanical and oxidation properties can be observed after irradiation due to the evolution of nano-precipitates under irradiation. The Small Angle Neutron Scattering (SANS) allows a very accurate description of the distribution of the secondary phases before and after irradiation.

In this article, examples of neutron utilisations for texture measurements, stress determination and microstructural characterisation by SANS are given, particularly for two main components of nuclear reactors (GEN 2\&3 and future GEN4): pressure vessel (welding and base metal) and fuel cladding of the fuel assembly.

\section{Neutron experimental techniques, recall}

\subsection{Texture analyses}

The characterization of the texture is to identify the crystallites direction $\left(\mathrm{g}_{i}\right)$ defined relative to a reference associated with the sample and to determine the associated volume fractions or densities.

\footnotetext{
${ }^{\text {a }}$ Corresponding author: jean-luc.bechade@cea.fr
}

This is an Open Access article distributed under the terms of the Creative Commons Attribution License 4.0, which permits unrestricted use, distribution, and reproduction in any medium, provided the original work is properly cited. 

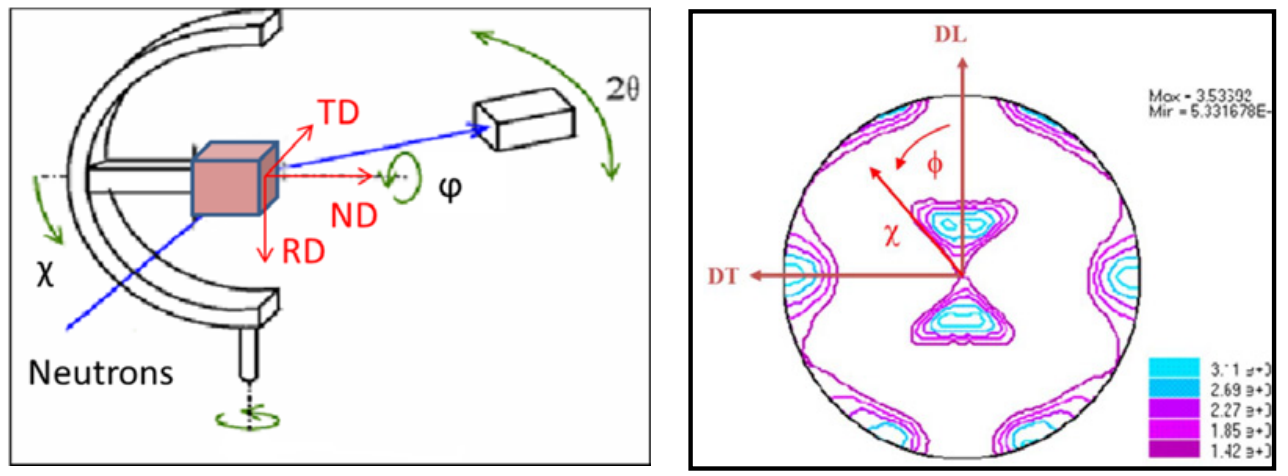

Figure 1. Goniometer with illustration of the sample rotations for texture measurement and example of a pole figure obtained by neutron diffraction.

There are different experimental methods, especially X-ray diffraction and neutron methods which are the most used because they provide a comprehensive and statistical description of the texture and are quite simple to implement.

The experimental determination of the crystallographic texture is to obtain pole figures. The direct pole figure (DPF) is the stereographic projection on the sample plane of the poles density distribution of a family of planes $\{\mathrm{hkl}\}$ in all directions of the sample. The X-ray diffraction or neutron represents the most common method to determine the pole figures.

Indeed, the principle is based on the fact that the intensity diffracted by a polycrystalline sample partly depends on the volume fraction of crystallites which satisfy the Bragg's law. In the presence of texture, the crystallite volume fraction varies with the orientation of the sample relative to the incident beam, which results in variations of diffracted intensity. The measurement of these variations of diffracted intensity by a family of planes $\{\mathrm{hkl}\}$ for successive sample orientations provides a pole figure $\{\mathrm{hkl}\}$. An example of experimental pole figure is given in Fig. 1.

The principles of Pole Figures analysis are similar to X-Rays pole figure measurements. The detector is set to the Bragg angle $2 \Theta$ corresponding to the selected lattice planes $\{\mathrm{hkl}\}$. The pole densities of this lattice planes for the different sample orientations are determined using a 4-cercles diffractometer whose goniometer allows rotating the sample around 2 axes. The reference frame tied to the sample is related to its thermomechanical history. Generally, in the case of sheet metal, the normal direction, the rolling direction and the transverse direction (ND, RD and TD respectively) constitute the main directions. The $\chi$ and $\varphi$ angles are the rotations about TD and ND and are reported on the illustration given below.

Although pole figures provide a useful qualitative description of the crystallographic texture, the information they contain is incomplete because each pole collects the contributions of crystallites with different crystallographic orientations obtained by a simple rotation of 0 to $2 \pi$ around the normal to the diffraction plane. A quantitative description of the texture of a sample is given by the crystallite Orientation Distribution Function. The calculation of this function requires several pole figures obtained on different lattice planes $\{\mathrm{hkl}\}$. The $\mathrm{ODF}(\mathrm{F}(\mathrm{g}))$ describes the frequency of occurrence of particular orientations ( $\mathrm{g}$ ) in a three-dimensional orientation space. This space is defined by three Euler angles which constitute a set of three consecutive rotations that must be given to each crystallite in order to bring its crystallographic axes into coincidence with the sample axes. The ODF is constituted by the set of the rotations associated to all the crystallites. Several mathematical models have been developed which allow the ODF calculation from several pole figures.

The advantages of neutron diffraction for determining textures are based on the very low absorption of neutrons by most of the materials. This property then allows to perform measurements in transmission 
and thus to obtain complete pole figures without other correction, that the subtraction of the background noise. The errors obtained on the calculated ODF are significantly lower than that deduced from with X-ray measurements. Moreover, due to the large size of neutron beams, volumes of the order of $\mathrm{cm}^{3}$ (approximately 100 times greater than RX) can be analysed. The advantages of neutron diffraction are undeniable for the analysis of large grain materials $\left(\mathrm{mm}^{3}\right)$, the texture characterization minority phases (volume fraction of 1\%), the use of complex sample environments for in situ measurements (oven, cryostat, under load...). For example, the evolution of the texture may be monitored in situ during thermal treatment. Finally, in the case of heterogeneous materials, neutrons diffraction gives a comprehensive description of the crystallographic textures, averaged over large volumes, which can complete a local approach.

\subsection{Stress analyses}

This paragraph is a brief recall about the determination of residual stresses in polycrystalline materials using Neutron Diffraction (ND) techniques. For more details, one can refer to various references [1-5] and also [23] for generalities about stresses determination.

First of all, neutron diffraction techniques are powerful means for non-destructive in-depth determination of residual stresses. They are well adapted for stress determination for coarse microstructure (large grain size, with heterogeneities...) found for example after the welding.

The principle is the following: the elastic strains are derived from the changes in the lattice spacings of the crystalline material. When a crystalline material is analysed with a neutron beam of wavelength $\lambda$, comparable with the inter-planer spacing $\mathrm{d}_{\mathrm{hkl}}$, a diffraction pattern is observed in which, the position of each plane (hkl) is obtained using the Bragg relation,

$$
2 \mathrm{~d}_{\mathrm{hkl}} \sin \theta_{\mathrm{hkl}}=\lambda
$$

The strain is measured in the direction of the scattering vector, $\mathrm{Q}=\mathrm{k}_{\mathrm{f}}-\mathrm{k}_{\mathrm{i}}$, which bisects the angle between incident and diffracted beams and is perpendicular to the diffracting planes. Lattice spacings are determined from the measured angular position of the diffraction peak (Bragg reflection) by irradiating the specimen with a monochromatic collimated beam of neutrons. If the specimen contains no strain, the lattice spacings are the strain free (stress free) values for the material and are denoted by $\mathrm{d}_{0, \mathrm{hkl}}$. In a stressed specimen, lattice spacings are altered and a shift in each Bragg peak position occurs and the elastic strains then are given by the change in peak position from stress-free location:

$$
\varepsilon_{\mathrm{hkl}}=\frac{\mathrm{d}_{\mathrm{hkl}}-\mathrm{d}_{0, \mathrm{hkl}}}{\mathrm{d}_{0, \mathrm{hkl}}}=\frac{\Delta \mathrm{d}_{\mathrm{hkl}}}{\mathrm{d}_{0, \mathrm{hkl}}}=\frac{\sin \theta_{0, \mathrm{hkl}}}{\sin \theta_{\mathrm{hkl}}}-1
$$

The angle $\theta_{0, \mathrm{hk} l}$ is the angle at which Bragg peak is observed from the strain free reference.

The angular resolution necessary to determine a strain $\varepsilon$ is derived from the Bragg equation and is given by $\Delta \theta_{\mathrm{hkl}}=-\varepsilon_{\mathrm{hkl}} \tan \theta_{h k l}$. The necessary information comes from the shift of the peak and not from its absolute position value.

An instrument used for strain measurement at a reactor source is shown schematically in Fig. 2.

The polychromatic neutron beam is first monochromated to a chosen wavelength by diffraction from a suitable monochromator. The divergence and size of the monochromatic beam is suitably adjusted using appropriate neutron optical devices and is then diffracted from the specimen. In a similar way, the diffracted beam is shaped using suitable optical devices, before being captured by the neutron detector. The gauge volume over which the strain measurement is made is given by the intersection of the incident and diffracted beams (Fig. 3). 


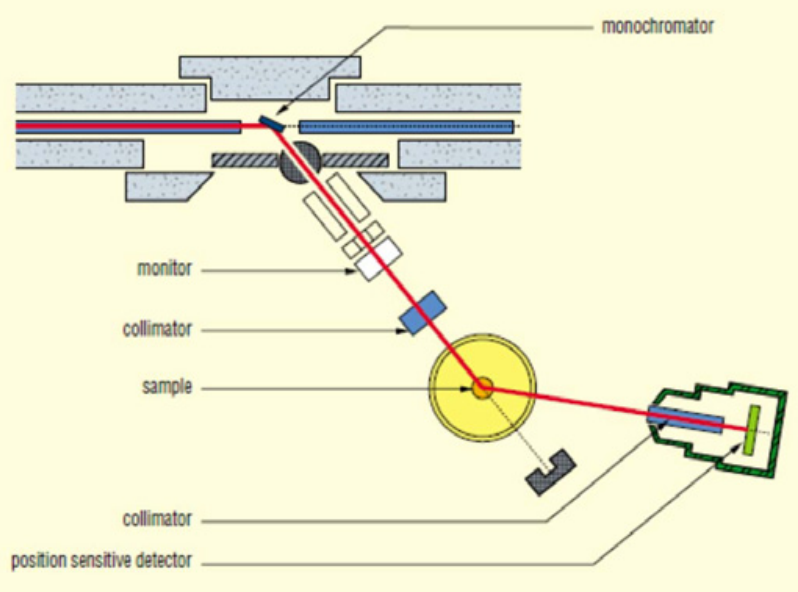

Figure 2. General layout of the diffractometer G 5.2 used for residual stresses analyses at LLB-Orphée.

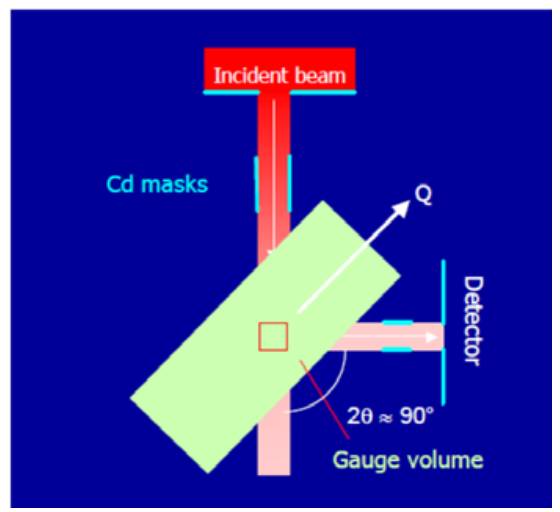

Figure 3. Definition of the gage volume for residual stress analyses.

Since neutron diffraction can measure the elastic strain within a defined volume in a crystalline solid, it is possible to calculate the mean stress in that volume through the incorporation of the elastic properties of the material given by the Hook's law.

Converting strain to stress from Hooke's law:

$$
\sigma_{\mathrm{ij}}=\frac{\mathrm{E}}{1+\mathrm{v}}\left[\varepsilon_{\mathrm{ij}}+\delta_{\mathrm{ij}}\left(\frac{\mathrm{v}}{1-2 \mathrm{v}}\right)\left(\varepsilon_{11}+\varepsilon_{22}+\varepsilon_{33}\right)\right]
$$

- $\mathrm{S}_{\mathrm{i}}, \mathrm{L}_{\mathrm{i}}$ are the sample and laboratory systems, respectively, and are related by $\phi$ and $\psi$.

- The diffracting planes are normal to $L$

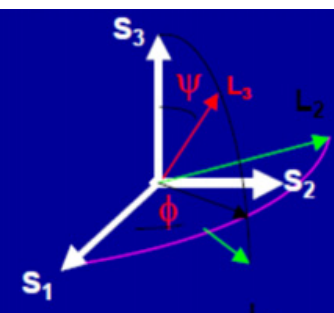




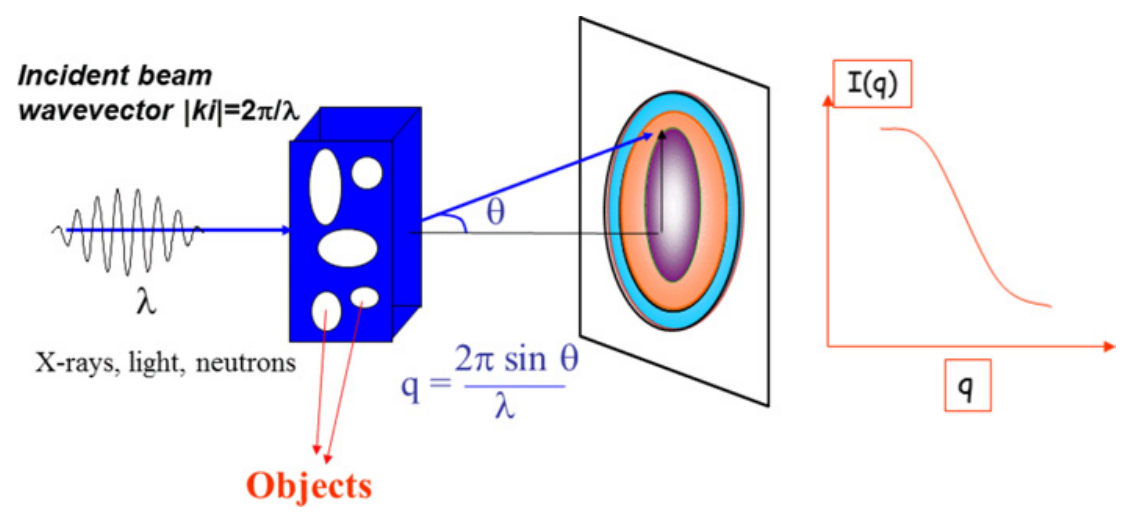

Figure 4. Principle of the Small Angle Neutron Scattering (SANS) experiment.

$$
\begin{aligned}
\varepsilon_{\varphi \Psi}= & \frac{1+\mathrm{v}_{\mathrm{hkl}}}{\mathrm{E}_{\mathrm{hkl}}}\left(\sigma_{\mathrm{xx}} \cos ^{2} \varphi \sin ^{2} \Psi+\sigma_{\mathrm{yy}} \sin ^{2} \varphi \sin ^{2} \Psi+\sigma_{\mathrm{zz}} \cos ^{2} \Psi+\sigma_{\mathrm{xy}} \sin 2 \varphi \sin ^{2} \Psi\right. \\
& \left.+\sigma_{\mathrm{xz}} \sin 2 \varphi \sin ^{2} \Psi+\sigma_{\mathrm{yz}} \sin \varphi \sin 2 \Psi\right)-\frac{\mathrm{v}_{\mathrm{hkl}}}{\mathrm{E}_{\mathrm{hkl}}}\left(\sigma_{\mathrm{xx}}+\sigma_{\mathrm{yy}}+\sigma_{\mathrm{zz}}\right)
\end{aligned}
$$

Full determination of the strain tensor (general triaxial stress state) requires measurements of the elastic strain in at least six independent directions, leading to strain/stress analyses even in the depth of the material (up to $\sim 1-2 \mathrm{~cm}$ ) which is not possible for conventional X-Ray Diffraction (XRD) experiments (analyses only at the surface, few microns depth). For biaxial stress state, the well-known $\sin ^{2} \Psi$ method can be used, with limitations in case of texture effects and/or gradients.

By translating the specimen through a highly collimated neutron beam, stresses within a small volume (around $1 \mathrm{~mm}^{3}$ for the best cases) can be determined at different locations in the specimen, thanks to linear translation and rotation tables, on which the specimen is mounted. By sequentially moving the specimen through the gauge volume the spatial variation in stress can be mapped. At the end the accuracy for strain measurement reaches $5.10^{-4}$, the stress value, depending on the material studied, is typically around $\pm 20 \mathrm{MPa}$.

\subsection{Small angle neutron scattering analyses}

Small Angle Neutron Scattering (SANS) is a key tool in material science to study the nano-precipitation. This method allows characterization, in a non-destructive way, of small particles (precipitates, cavities...) ranging in size between 1 and $100 \mathrm{~nm}$. This technique giving statistical data representative of the whole sample is particularly well adapted to the study of steels. Indeed, neutron radiation provides often a large contrast between chemical elements, that are neighbor in the periodic table $(\mathrm{Fe}, \mathrm{Cr}, \mathrm{Mn}$, $\mathrm{Ni}$...) or light elements $(\mathrm{C}, \mathrm{N}, \mathrm{O}, \mathrm{H})$. In addition, the magnetic scattering also provides, in the case of a ferromagnetic material, additional information.

The principle of the technique is as follows: if a monochromatic beam of thermal neutrons is sent on a solid sample containing heterogeneities or nanoparticles, the transmitted beam is broadened, and this broadening is roughly inversely proportional to the average particle size (Fig. 4).

In the case of the two phase's model, the SANS intensity per unit volume can be written as $[7,8]$ :

$$
\mathrm{I}(\mathrm{q})=\Delta \rho^{2} \times \mathrm{Np} \times \mathrm{Vp}^{2} \times \mathrm{F}(\mathrm{q}) \times \mathrm{S}(\mathrm{q})
$$

where $N_{p}$ is the number density of scattering particles, $V_{p}$ the particle volume. $q=4 \pi \sin \theta / \lambda$ where $2 \theta$ is the scattering angle. 
$\Delta \rho$ is the nuclear contrast defined by:

$$
\Delta \rho=\frac{b^{p}}{v_{a t}^{p}}-\frac{b^{m}}{v_{a t}^{m}}
$$

where $\mathrm{b}^{p, m}$ is the average scattering length and $v_{a t}^{p, m}$ the average atomic volume in the precipitates (p) or in the matrix $(\mathrm{m}) . \mathrm{F}(\mathrm{q})$ is the form factor of the particles. $\mathrm{S}(\mathrm{q})$ is the interference term between precipitates. In many systems, the precipitates are supposed to be spherical particles of radius $\mathrm{R}$ and, consequently, their form factor $\mathrm{F}(\mathrm{q}, \mathrm{R})$ is given by:

$$
F(q, r)=\left[3 \frac{\sin (q r)-q r \cos (q r)}{(q r)^{3}}\right]^{2}
$$

$\mathrm{S}(\mathbf{q}, \mathrm{R})$ is the interference term between precipitates, which is not negligible for a precipitated fraction larger than 1\%; a formulation which is commonly used in solid system, is the structure factor for a liquid-like arrangement of hard spheres, calculated analytically by Ashcroft and Lekner [9] from the Percus-Yevick equation. Moreover, generally, the particles sizes are not mono-disperse, so the SANS intensity includes a size distribution function $h(R)$. To model the scattering intensity, usually a $\log$ normal or a Gaussian distribution is taken for $h(R)$.

In these conditions, Eq. (5) becomes:

$$
\mathrm{I}(\mathrm{q})=\Delta \rho^{2} \mathrm{f}_{\mathrm{V}} \frac{\int_{0}^{\infty} \mathrm{h}(\mathrm{R}) \mathrm{V}_{\mathrm{p}}^{2} F(q, R) S(q, R) d R}{\int_{0}^{\infty} h(R) V_{p} d R}
$$

where $f_{v}$ is the volume fraction of precipitates.

In the case of ferromagnetic materials, the SANS intensity is composed also of a magnetic contribution which depends on the difference of magnetisation between particles and matrix. In terms of cross-section, the SANS intensity (5) can be written as [10]:

$$
(d \Sigma / d \Omega)(q) \approx f_{p}\left[\Delta \rho_{\text {nucl }}^{2}+\Delta \rho_{\text {mag }}^{2} \sin ^{2} \alpha\right] F(q, h(R), S(q, R))
$$

$\alpha$ is the angle between the magnetization of the sample and the scattering vector $q$ and the magnetic contrast is calculated as the nuclear contrast. The "magnetic scattering length" depends on the magnetization and is defined by $b_{\text {mag, matrix }}=-\gamma \mathrm{r}_{0} / 2 \mu$ where $\gamma=-1.913$ is the gyromagnetic factor of the neutron, $\mathrm{r}_{0}=0.2818 \times 10^{-14} \mathrm{~m}$ is the classical electron radius and $\mu$ is the mean magnetic moment of atoms.

As the experiment is performed under saturating magnetic field, the atomic magnetic moments are aligned along the applied magnetic field. So the angle $\alpha$ is known and the scattered intensities obtained in the two perpendicular directions ( $\perp$ and // to H) corresponding to $\alpha=90$ and $\alpha=0$ can be considered separately. The difference of these two contributions gives the magnetic scattering:

$$
(d \Sigma / d \Omega)(q) \approx f_{p} \Delta \rho_{\text {mag }}^{2} F^{2}(q, R, h(R))
$$

The ratio between these two contributions is called "A ratio". For homogeneous particles with sharp interface, it depends only on the chemical composition, magnetization and atomic density variations between precipitates and the matrix, and is given by:

$$
\mathrm{A}=\frac{(\mathrm{d} \Sigma / \mathrm{d} \Omega)_{\perp \overrightarrow{\mathrm{H}}}}{(\mathrm{d} \Sigma / \mathrm{d} \Omega)_{/ / \overrightarrow{\mathrm{H}}}}=\frac{\Delta \rho_{\mathrm{nucl}}^{2}+\Delta \rho_{\mathrm{mag}}^{2}}{\Delta \rho_{\text {nucl }}^{2}}=1+\frac{\Delta \rho_{\mathrm{mag}}^{2}}{\Delta \rho_{\text {nucl }}^{2}}
$$

This ratio can provide information about the chemical composition of the particles. 


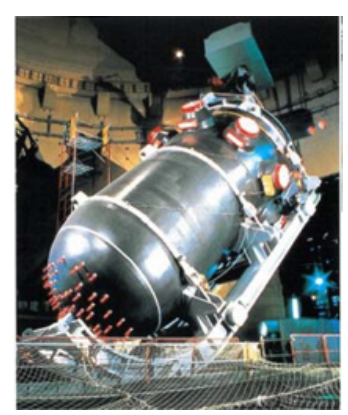

(a)

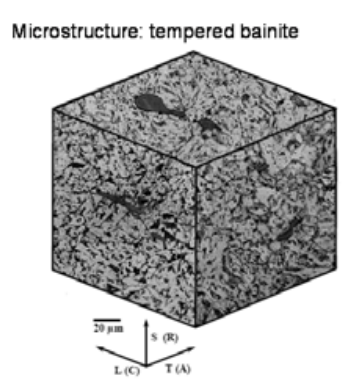

(b)

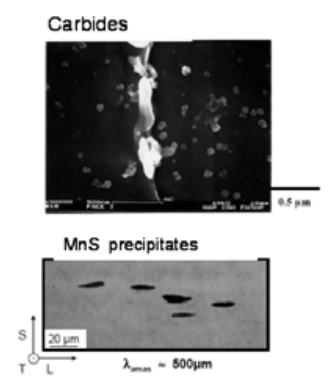

Figure 5. Picture of the pressure vessel of PWR (a) and microstructure of the bainitic steel used for the RPV (b).

All SANS experiments presented in this paper, were performed at the Laboratoire Léon Brillouin (CEA CNRS), Saclay, on PAXY and PAXE small-angle instruments. Generally, two configurations defined by the wavelength $(\lambda)$ and the sample-to-detector distance, are necessary to study a precipitate size range between $0.5 \mathrm{~nm}$ to about $20-30 \mathrm{~nm}: 0.6 \mathrm{~nm} / 2 \mathrm{~m}$ and $0.9 \mathrm{~nm} / 5 \mathrm{~m}$ covering a scattering vector (q) range from 0.08 to $1.6 \mathrm{~nm}^{1}$.

\section{Application to nuclear materials}

\subsection{The pressure vessel}

\subsubsection{Texture analyses for bainitic steel (Pressurized Water Reactor)}

French Reactor Pressure Vessel (RPV) steels (16MND5 showing bainitic microstructure) of Pressurized Water Reactor (PWR) are subjected to temperature and neutron irradiation during the life of the nuclear plant. One consequence of this long term exposure to neutron irradiation is the embrittlement of the pressure vessel steel, Fig. 5a. To guaranty the integrity of the plant, the methodologies used worldwide require continuous validation through surveillance programs. Recent and significant progress in material science and computation techniques give the opportunity to increase the accuracy of the methods trough the development of physic models.

A new methodology associating texture determinations and strains measurements by neutron diffraction in order to analyse the stress fields within families of crystallites with the same crystallographic orientation in polycrystalline materials, has been proposed at CEA [11]. This stress analysis method allows an intermediate approach between a local and a global scale characterization within the bulk of massive samples. It provides statistically representative information and appears promising for coupling with modelling methods.

To develop this approach, it was first necessary to analyse the texture of the material studied. For this bainitic microstructure showing large heterogeneities (Fig. 5b) it was essential to get representative description of the crystallographic texture. Comparisons between XRD and Neutron Diffraction textures analyses have been performed: XRD providing texture analyses only at the surface of the sample (few microns depth and here the surface analysed was about $1 \mathrm{~cm}^{2}$ ) and ND proving texture information for $1 \mathrm{~cm}^{3}$, up to $\sim 1 \mathrm{~cm}$ in the depth and with a better statistic compared to XRD.

2 pole figures were measured, the (110) because plastic deformation with dislocation gliding occur in this plane, and the (200) because cleavage is favoured in the (100) plane (Fig. 6). These texture analyse were performed for as received material (bainitic structure) but also after deformation of $7.5 \%$ (plastic deformation) at $20^{\circ} \mathrm{C}$ and $-60^{\circ} \mathrm{C}$ in order to get access to plastic deformation heterogeneity for specific crystallographic orientation as described in Daklhoui paper [11]. 


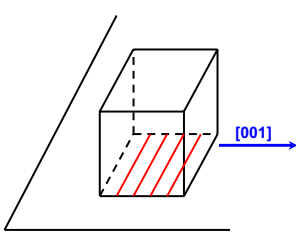

$(100)[001]$

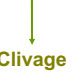

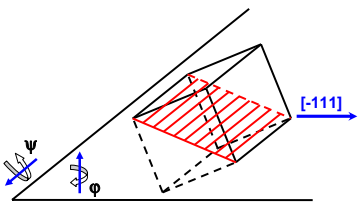

$(110)[-111]$

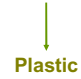

deformation

Figure 6. Crystallographic planes analysed for bainitic steel.

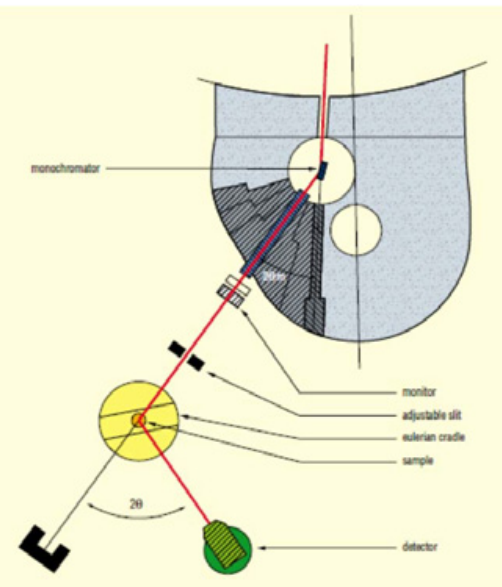

Figure 7. General layout of the diffractometer 6T1 used for texture analyses at LLB-Orphée.

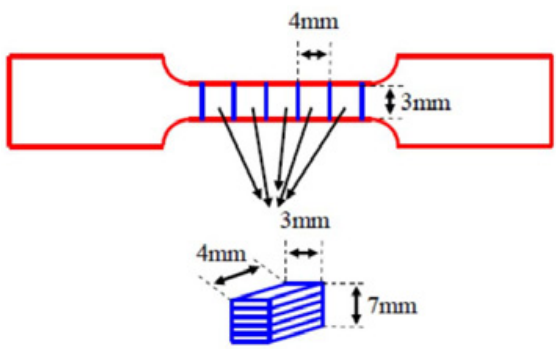

Figure 8. Tensile specimen used for texture analyses.

Textures with XRD have been performed with conventional XRD diffractometer for texture analyses (4 circles, with Eulerian cradle using $\mathrm{Cu}$ radiation in reflexion mode). For ND texture analyses, they have been performed at CEA-Saclay, LLB-Orphée, using 6T1 spectrometer: four circle diffractometer, dedicated to pole figure determination. The neutron wavelength was $0.1159 \mathrm{~nm}$ selected by a $\mathrm{Cu}\left(\begin{array}{lll}1 & 1 & 1\end{array}\right)$ monochromator (Fig. 7) [12].

The sample was a composite sample, $4 \times 3 \times 7 \mathrm{~mm}^{3}$. 


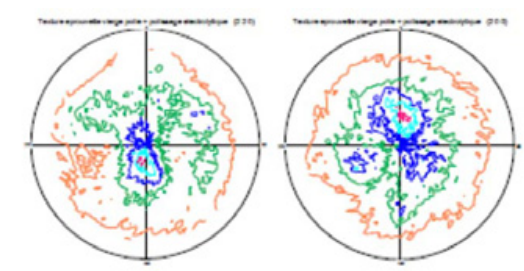

(a)

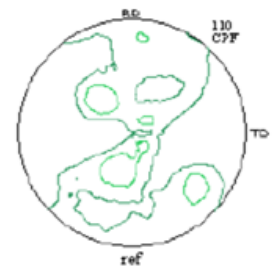

(b)
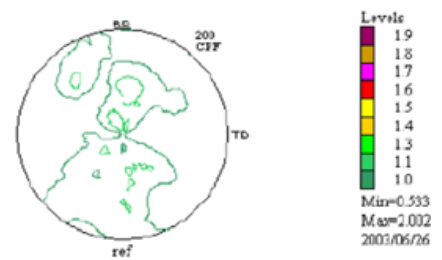

Figure 9. Pole figures obtained for the bainitic steel in the as received structure from XRD analyses (a) and ND analyses (b).



(a)
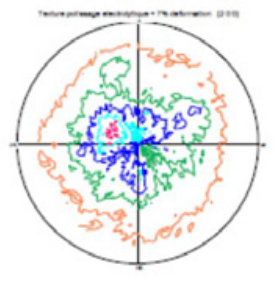

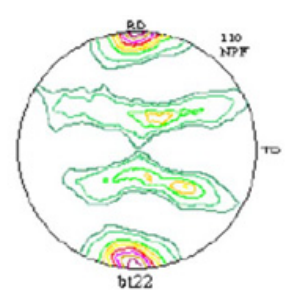

(b)
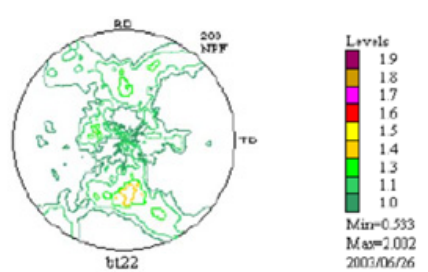

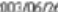

Figure 10. Pole figures obtained for the bainitic steel after deformation at $20^{\circ} \mathrm{C}$ from XRD analyses (a) and ND analyses (b).

As described in Fig. 8, the sample was obtained after tensile test up to $7.5 \%$ plastic deformation at $20^{\circ} \mathrm{C}$ and $-60{ }^{\circ} \mathrm{C}$. A reference sample, in as received conditions, was also prepared in order to have the initial state without any deformation.

Texture analyses for the as-received material (bainitic structure) are quite similar between XRD and ND: quite random texture, without preferred orientation (Fig. 9).

After plastic deformation at $20^{\circ} \mathrm{C}$ and $-60^{\circ} \mathrm{C}$, differences appear between the ND and XRD.

From XRD analyses texture seem to be unchanged; whereas using ND preferred orientation seem to appear after $7.5 \%$ plastic deformation (Figs. 10 and 11).

As a conclusion, results clearly show that ND has to be used in this case; XRD does not provide representative description of what happens in the bulk material, in contrary to ND.

\subsubsection{Texture analyses for austenitic stainless steel used for welding (Sodium Cooled Fast Reactor)}

Weld material of type 316L is employed in making the welded joints of fast breeder reactors. Compositions of filler metals have been optimised in order to limit the thickness and the strength of components with welds in the licensing procedure. The microstructure of as-welded 316L deposit consists of two phases: columnar grains of $\gamma$-austenite constitute a matrix where thin dendrites of $\delta$-ferrite can be found. The texture resulting from the solidification process of both phases respects often Kurdjumov-Sachs (KS) or Nishiyama-Wassermann (NW) misorientation relationships. They may induce anisotropy in the creep behaviour which has been experimentally observed and reported elsewhere [12].

The purpose of the study performed during $\mathrm{G}$ Bouche $\mathrm{PhD}$ [13] was to analyse the texture of the material in order to assess the influence of the crystallographic texture upon creep behaviour and localisation of damage initiation. 

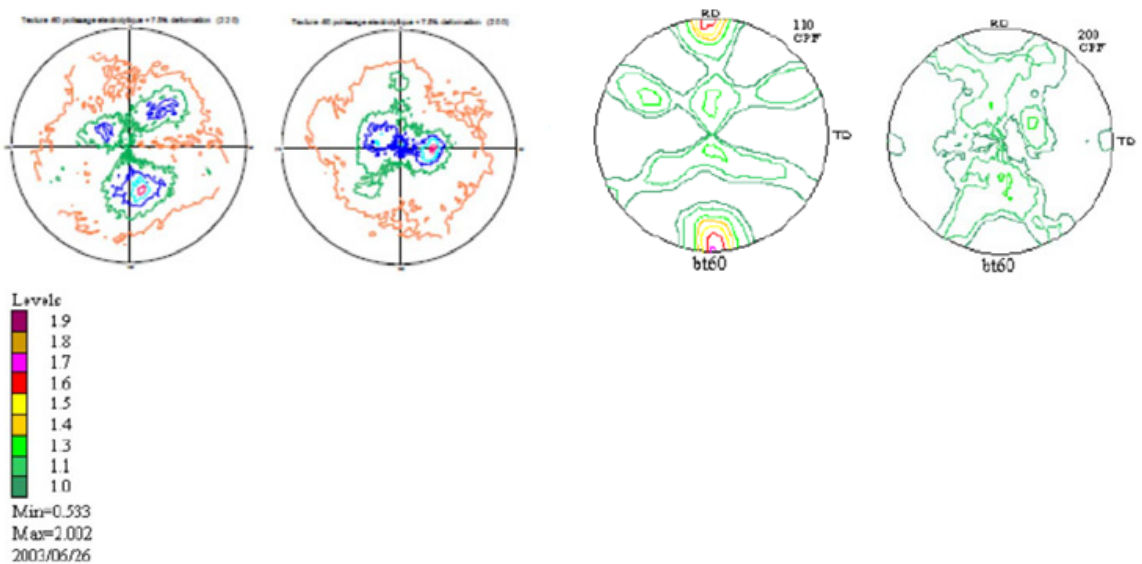

(a)

(b)

Figure 11. Pole figures obtained for the bainitic steel after deformation at $-60^{\circ} \mathrm{C}$ from XRD analyses (a) and (b) ND analyses.
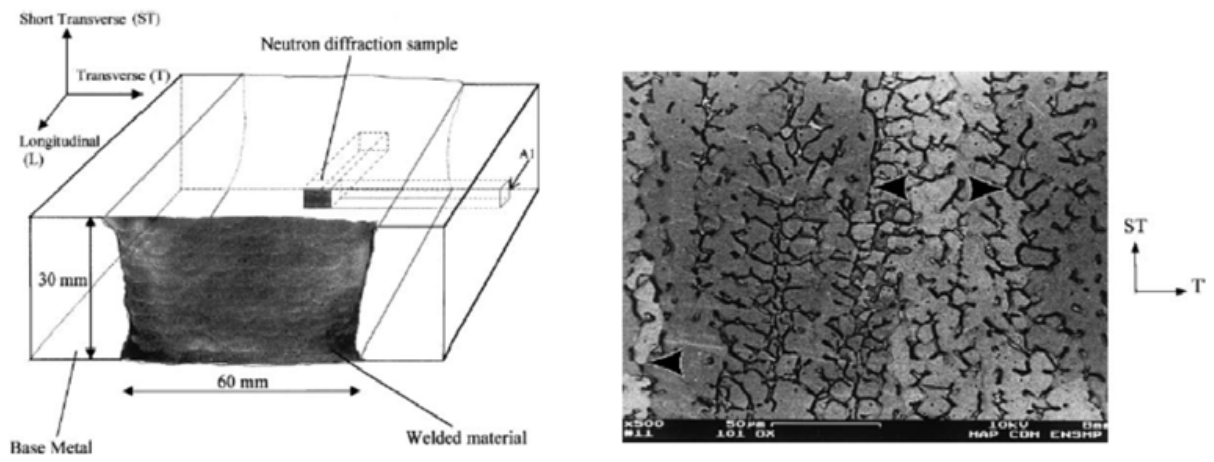

Figure 12. Sketch of the $316 \mathrm{~L}$ mould and location of samples used in the present study.

As it is difficult to cut test specimens from an $\mathrm{X}$ weldment, the two-phase microstructure of 316L welds was simulated by manually filling a mould with longitudinally deposited weld beads. The crystallographic texture of the material was then investigated on the basis of a multiscale approach, using neutron Electron Backscattered Diffraction (EBSD) and Transmission Electron Microscopy TEM. It was especially important to have access to volumic analyses using ND, first of all because no surface preparation is required for the sample and secondly, the analysed volume can be up to $1 \mathrm{~cm}^{3}$. It gives a very good statistics on texture for material with large grains compared to small-scale investigations. In the case of the weld metal, $\gamma$ grains can be as long as $1 \mathrm{~cm}$ in the direction of solidification. Furthermore, the neutron diffraction technique is very sensitive to small amount of second minor phase, here ferrite $(<7 \mathrm{wt} \%)$.

The experiments were also performed at CEA-Saclay with 6T1 spectrometer with similar conditions. The sample was a cube of $0.6 \mathrm{~cm}$ edge. Its position and orientation in the mould are given in Fig. 12 .

The diffraction pattern presented in Fig. 13 shows the diffraction peaks related to both $\delta$ and $\gamma$ phases.

Next stage in the neutron diffraction analysis was to determine pole figures for the two phases. Experimental pole figures for each phase are presented in Figs. 14 and 15, respectively, (111), (200), 


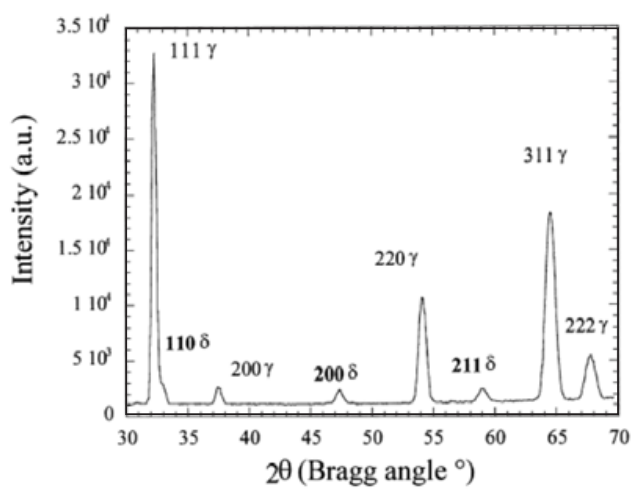

Figure 13. Neutron diffraction pattern showing the two phases.
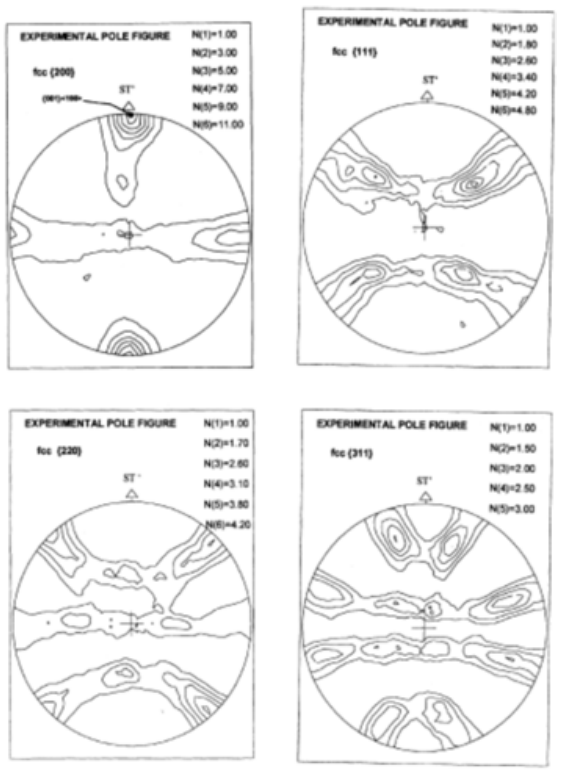

Figure 14. Pole figures obtained for austenite by neutron diffraction analysis.

(220) and (311) pole figures for $\gamma$ and (110), (200) and (211) pole figures for $\delta$. These pole figures are not in the plane of the A1 surface (Fig. 12) but have been tilted to have the growing direction of the grains perpendicular to the pole figure. This enabled to calculate the exact angular deviation $\alpha$ between the $<100>$ direction of solidification and the Short Transverse direction of the mould.

The figures obtained are the ones of a fibre-like $<100>$ texture with reinforcements, and $\gamma-\alpha$ pole figures are very similar. It clearly appears that the growing direction of the grains is of a type $<100>$ parallel to ST' (which is the transformation of ST after 2 rotations linked to the rotation defined above). The skeleton line, presented in Fig. 16, which gives the values of the ODF along a specifically chosen linear path through the orientation space (here for $\varphi=0, \Psi=90$ and $\theta$ ranging from $0^{\circ}$ to $180^{\circ}$ ), confirms the similarity between $\gamma$ and $\delta$ pole figures. This plot also shows that the main orientation, $(001)<100>$, is a little bit stronger for the $\gamma$ phase. As a consequence it comes out that on the macroscopic scale the phases are not in a classical orientation relationship like KS or NW but more in a cube \pm cube one. 

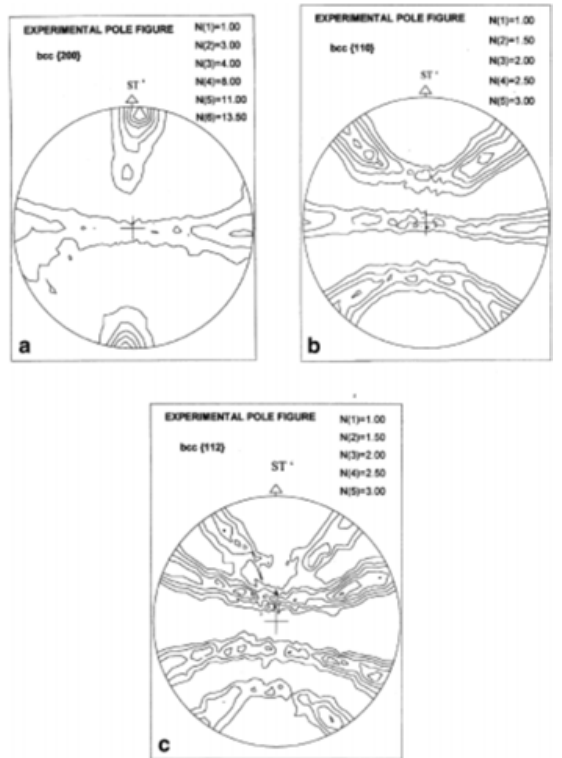

Figure 15. Pole figures obtained for ferrite by neutron diffraction analysis.

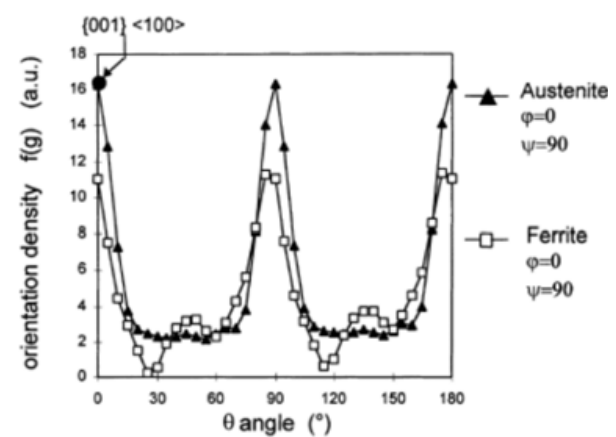

Figure 16. Skeleton line of the $\mathrm{ODF}$ for $\varphi=0, \Psi=90$ and $\theta$ ranging from $0^{\circ}$ to $180^{\circ}$.

As a conclusion, the minor ( $<7 \mathrm{wt} . \%)$ ferritic phase could be obtained thanks to neutron diffraction analysis thus allowing a quantitative texture study of that phase, with a very important result: the pole figures obtained for ferrite are very similar to the ones obtained for austenite, showing that $\delta$ and $\gamma$ are mainly in a cube \pm cube misorientation relationship. Similar results were obtained at more local scale (TEM and EBSD). This has been interpreted in terms of the solidification mechanism: both ferrite and austenite cubes mostly nucleate and grow in parallel; then, upon cooling, plasticity occurred to accommodate the difference in the thermal expansion coefficients of both phases. This plasticity led to a misorientation (of up to $15^{\circ}$ ) between both phases.

\subsubsection{Stress analyses after welding of martensitic steel (Gas Cooled Fast Reactor)}

For reactors of $4^{\text {th }}$ generation, GFR (Gas cooled Fast Reactor) and HTR (High Temperature Reactor), T91 grade steel $(\mathrm{Fe}-9 \mathrm{Cr}-1 \mathrm{MoVNb})$ is considered as the reference material for the Reactor Pressure Vessel. This steel with high mechanical properties (excellent mechanical properties at high temperature such as toughness), especially negligible creep deformation compared to bainitic steel used for PWR, 


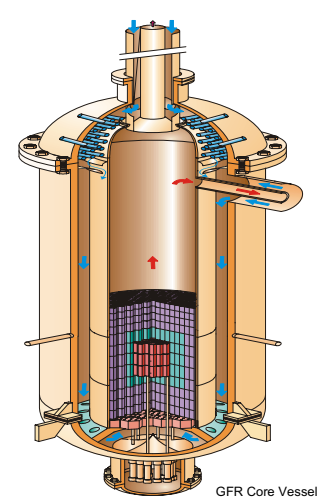

Figure 17. Schematic view of GFR core vessel.
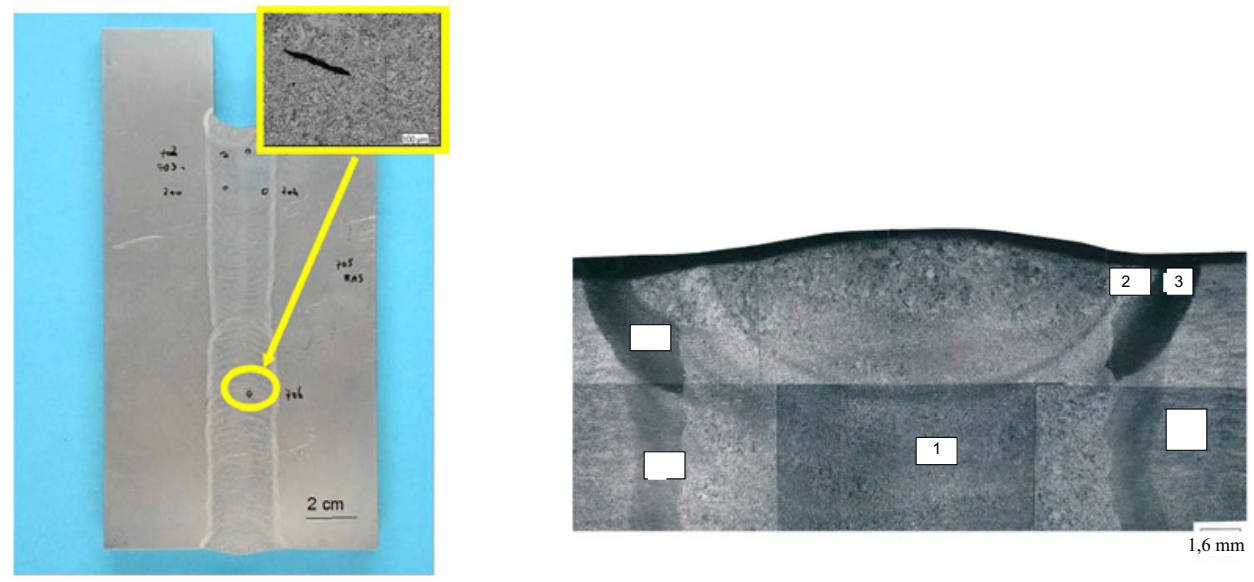

Figure 18. Picture representatives of the welding process for thick pieces of T91 steel.

would have to be welded: thick rings would be joined by welding to obtain the pressure vessel for HTR or GFR (Fig. 17).

During this fabrication process, complex phenomenon occur (creation and cooling of melted area, phase transformation in the welded bead and in the Heat Affected Zone (HAZ)...). The weld process retain at the present time is TIG (Tungsten Inert Gas), leading in particular conditions to cracks in the vicinity of the weld bead, obviously not acceptable. Residual stresses created during the welding process are crucial parameters to understand the crack phenomenon and are probably at the origin of the rupture occurring in that case (Fig. 18).

In that frame representative pieces of welded T91 steels have been supplied (the weld joint is nearly of the same composition compared to T91), thick pieces of metal, in order to determine residual stresses after welding in various conditions, before-after heat treatment (stress annealing of the component after the welding is performed, but not too high in order to avoid any decrease of the mechanical properties such as impact strength for the vessel). Finite element calculations have been performed and experimental approach was asked in order to validate the modelling approach.

XRD stress analyses have already been performed after similar welding process for austenitic steels but results were not concluding certainly due to the coarse microstructure (grains size) in the HAZ leading to only few grains analysed in the diffracting volume. 


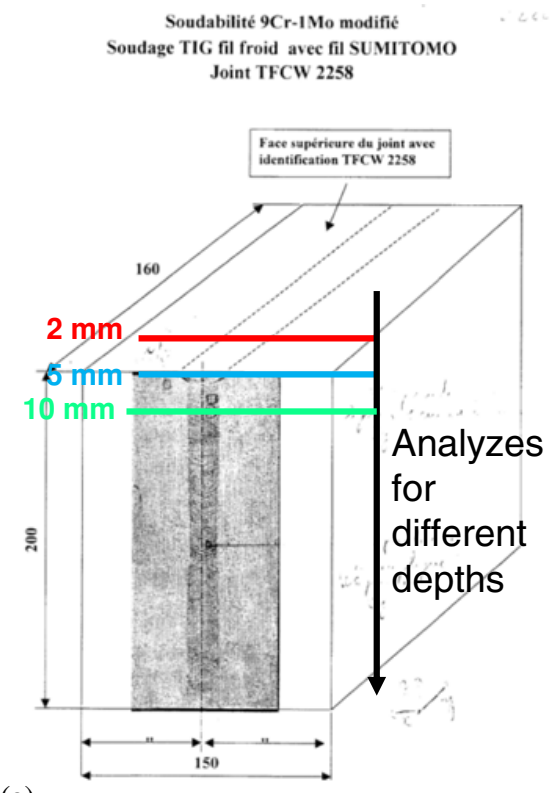

(a)

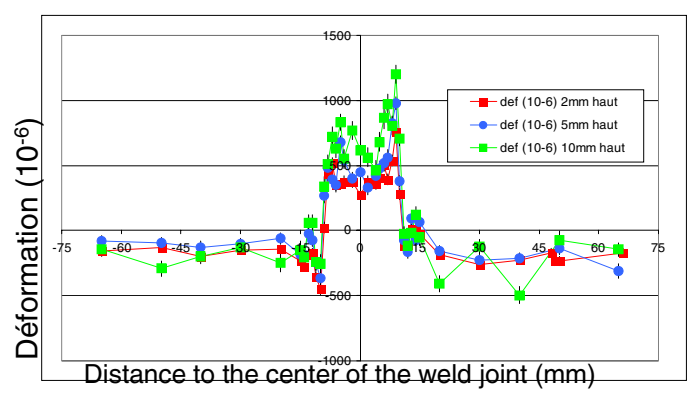

(b)

Figure 19. Sample analysed for residual stress determination (a) and deformations measured before thermal treatments at different locations (b).

In that case we propose to use ND to solve this problem, with also the great advantage of proving the full stress tensor, even in the depth of the material.

The sample prepared for this study (Fig. 19a) was prepared with a thick piece of metal $(\sim 30 \mathrm{~kg}$ weight) showing a large weld joint (same composition of the base metal) in his centre.

Stress analyses were performed at LLB-Orphée, G5.2 spectrometer (already presented in the introduction) at three different depths: 2, 5 and $10 \mathrm{~mm}$ with following conditions:

- volume analysed: $2 \times 2 \times 2 \mathrm{~mm}^{3}$;

- wavelength: $0.284 \mathrm{~nm}$;

- diffracting plane $\mathrm{Fe}(111), 2 \theta \approx 89^{\circ}$;

- reference samples for stress free sample: a cube of metal was machined in the weld joint and base metal.

Results are given Fig. 19b in term of deformation, before any calculation (using continuous medium mechanic laws) to obtain the stress state, in the weld joint and HAZ. High deformation level, in tension, can be reached especially at $10 \mathrm{~mm}$ depth (a simple calculation gives $\sim 200 \mathrm{MPa}$ in the weld joint). Next step for this study will be to reduce this quite high level of internal stress with an appropriate heat treatment.

Thanks to ND, this experimental data can be directly compared to Finite Element modelling in order to precise and define the parameters of the macroscopic calculation.

\subsubsection{SANS analyses of martensitic steels before and after irradiation (Gas Cooled Fast Reactor) [9, 10]}

Martensitic steels with 7-12 wt\% Cr are candidates for the internal structures of future generation nuclear reactors or spallation sources, because of their remarkable mechanical properties and resistance 


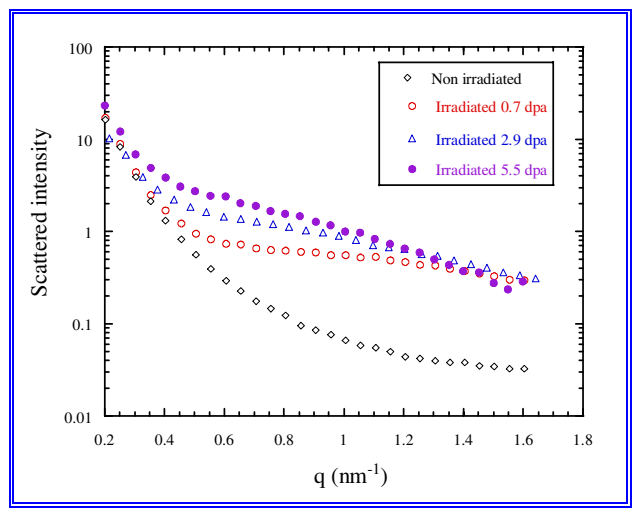

Figure 20. Scattered intensities perpendicular to the applied magnetic field, measured on LA4Ta samples (Fe$11 \% \mathrm{Cr}$ ), irradiated $0.7,2.9$ and $5.5 \mathrm{dpa}$ at $325^{\circ} \mathrm{C}$ and not irradiated.

to swelling; but they suffer from radiation hardening and embrittlement below $400{ }^{\circ} \mathrm{C}$, even at moderate doses. In order to promote their use, it is necessary to understand the evolution of their microstructure and its relationship with the degradation of mechanical properties during irradiation.

Two phenomena are particularly expected under neutron irradiation: the precipitation of the Cr-rich $\alpha^{\prime}$ phase and the formation of clusters of defects induced by the irradiation.

In this study, the phenomenon of unmixing of the b.c.c. Fe-Cr solid solution below $600{ }^{\circ} \mathrm{C}$ into two isomorphous phases, Fe-rich ( $\alpha$ phase) and Cr-rich ( $\alpha^{\prime}$ phase), observed in thermally-aged alloys with $\mathrm{Cr}$ content between 10 and 90 at.\%, was studied in different neutron irradiated steels with a $\mathrm{Cr}$ content between $7 \%$ and $12 \%$. The phase separation occurs at the nanometer scale and induces hardening of the solid solution. The first step of $\alpha^{\prime}$ precipitation could not be observed in martensitic/ferritic steels by Transmission Electron Microscopy (TEM). Small-Angle Neutron Scattering (SANS) is much more powerful to study the $\alpha-\alpha^{\prime}$ phase separation (an example is illustrated on Fig. ??), because of the large difference between the neutron coherent scattering lengths of Fe and Cr. Moreover, because the matrix is ferromagnetic, the magnetic and nuclear SANS intensities can be separated to obtain information on the chemical composition of the particles.

In the unirradiated state, all materials show a strong SANS signal due to the $\mathrm{M}_{23} \mathrm{C}_{6}$ carbides formed during initial thermal treatment; this $\mathrm{M}_{23} \mathrm{C}_{6}$ population does not evolve under irradiation. After irradiation, most samples display a supplementary SANS signal, mainly observed at large q; this shows that a new nanometer-sized precipitation has formed. As example, the increase in SANS signal between the LA4Ta steel (Fe-11Cr-0.7W) sample irradiated 0.7 dpa at $325^{\circ} \mathrm{C}$ and the as-received sample shows a broad maximum around $\mathrm{q} \sim 1.1 \mathrm{~nm}^{-1}$. This indicates a spatial periodicity in composition, with a characteristic length $2 \pi / \mathrm{q} \sim 5-6 \mathrm{~nm}$, similar to that observed in the thermally aged Fe-Cr solid solution. Moreover, the A value of the irradiation-induced SANS signal $(\mathrm{A}=1.9 \pm 0.2)$ is in agreement with $\alpha-\alpha^{\prime}$ phase separation of the ferritic matrix. The volume fraction of precipitated $\alpha^{\prime}$ phase increases with the irradiation dose (e.g. from $0.8 \%$ at $0.7 \mathrm{dpa}$ to $3.4 \%$ at $5.5 \mathrm{dpa}$ for LA4Ta at $325^{\circ} \mathrm{C}$ ). The mean size doesn't evolve and stay around $1-1.5 \mathrm{~nm}$.

Using irradiated steels of different compositions, it was possible, from the determination of the $\alpha^{\prime}$ volume fraction as a function of the nominal $\mathrm{Cr}$ content, to estimate the $\mathrm{Cr}$ threshold concentration in the ferrite for $\alpha-\alpha^{\prime}$ unmixing. The obtained values are 7.2 at. $\% \mathrm{Cr}$ at $325^{\circ} \mathrm{C}$ and 8.3 at. $\% \mathrm{Cr}$ at $400{ }^{\circ} \mathrm{C}$. The deduced values (data points (o) Fig. ??) are in agreement with the $\mathrm{Fe}-\mathrm{Cr}$ phase diagram calculated from thermodynamic data at high temperature. This last point let suppose that the precipitation mechanism is just accelerated by irradiation. 


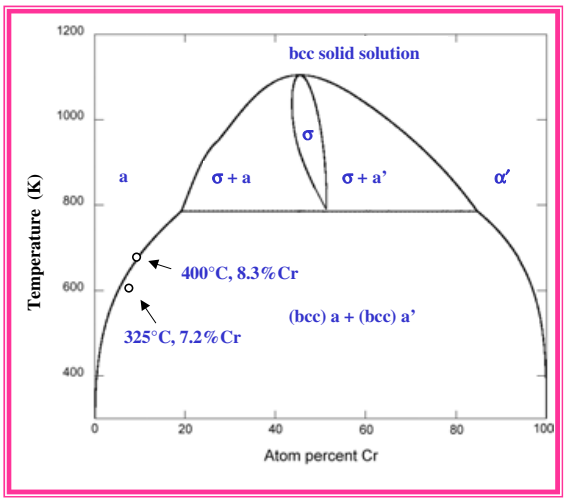

Figure 21. Fe-Cr binary phase diagram calculated from high temperature thermochemical data. Experimental points for the threshold of $\alpha^{\prime}$ precipitation in irradiated steels deduced from the present SANS study are reported.

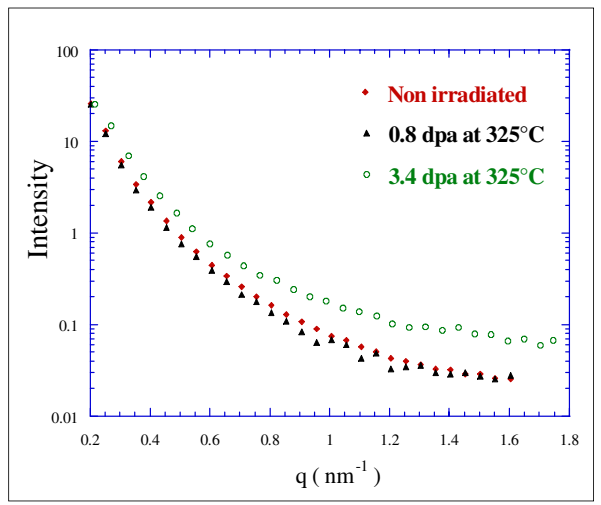

Figure 22. Scattered intensities perpendicular to the applied magnetic field, measured on $\mathrm{F} 82 \mathrm{H}$ samples (Fe$7.5 \% \mathrm{Cr}$ ), irradiated 0.7 , and $3.4 \mathrm{dpa}$ at $325^{\circ} \mathrm{C}$ and not irradiated.

For low chromium contents alloys ( $\leq 7.5 \mathrm{wt} . \%)$, a small increase of the SANS intensity is observed (Fig. ??). The A ratio value does not correspond to $\alpha$ ' precipitation, but is in agreement with vacancy clusters $(\mathrm{A}=1.4)$. These could be small cavities or dislocation loops which have been observed by TEM in the form of "black dots". Their number densities deduced from TEM and SANS data $(\approx 3 \times$ $10^{23} \mathrm{~m}^{-3}$ ) are in better agreement if the defect form factor is assumed to be cavity-like.

\subsection{Fuel cladding of the fuel assembly}

\subsubsection{Stress analyses after plastic deformation of Zr based alloys of PWR}

Zirconium alloys are widely used for structural applications in Light Water Reactors due to their excellent properties for nuclear applications. Zirconium, with its properties of very low thermal neutron capture cross section, good water corrosion resistance for in-service conditions $\left(\sim 350^{\circ} \mathrm{C}\right)$, stability of mechanical properties even under irradiation up to high doses is widely used for cladding and structural materials in the reactor core. Structural components of the fuel assembly include guide tubes, grids and fuel cladding tubes. In Pressurized Water Reactors (PWRs), fuel rods cladding tubes are about $4 \mathrm{~m}$ length with a diameter of about $9 \mathrm{~mm}$ and a thickness around $0.6 \mathrm{~mm}$ (Fig. ??). 


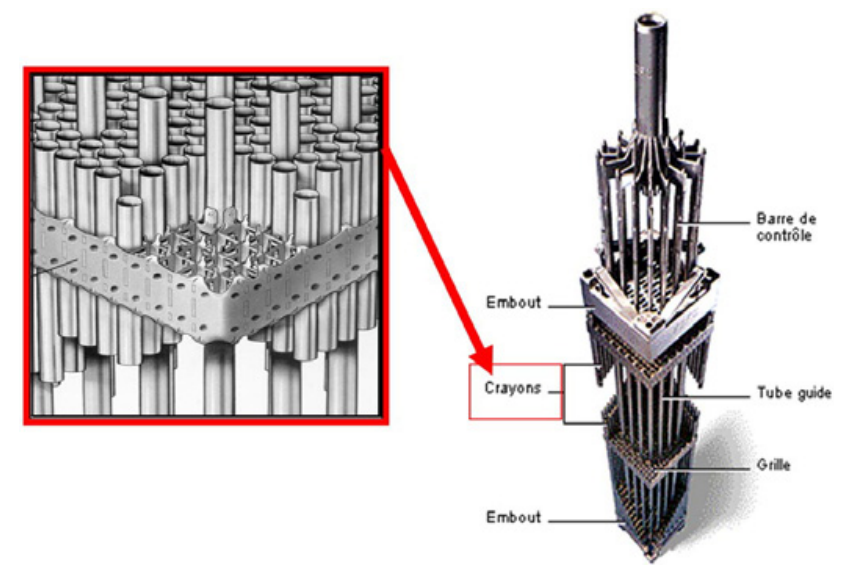

Figure 23. Zr based fuel assembly for PWR.

Under thermomechanical loading, zirconium alloys, showing high plastic anisotropy of slip systems, build up highly heterogeneous mechanical fields, which persist after unloading as far as inelastic deformations are involved. This heterogeneous distribution is characteristic of the local thermo-elastovisco-plastic anisotropy of the material, the microstructure, and the prescribed macroscopic loading path. It can be characterized in a statistical way at various scales, i.e. at the scale of a lattice defect (nm), a grain $(\mu \mathrm{m})$, or a representative volume element $(\mathrm{mm})$ by means of appropriated average operators. For the mean residual stress within different subgrains of a same grain can vary significantly after plastic deformation, by about $100 \mathrm{MPa}$ [11]. This heterogeneous stress distribution must be considered when identifying the local constitutive relation on in situ measurements [12]. The distribution of residual elastic strain in polycrystals can be best analysed by the diffraction technique (line "position"). Furthermore, using neutrons, real volume analysis can be carried out due to their large penetration depth. However, the heterogeneous character of the elastic strain field is never completely taken into account in the analysis of experimental data, especially using diffraction techniques, classically using $\sin ^{2} \Psi$ law. Homogenization techniques, such as the self-consistent scheme, are required to describe the strain heterogeneity.

During N Letouzé's PhD work [13] neutron scattering have been used at LLB-Orphée with 6T1 spectrometer, providing a volume measurement of the elastic strain distribution in a creep deformed Zircaloy-4 specimen. Phase average elastic strains have been measured and compared with the prediction of the affine self-consistent scheme for nonlinear elasto-viscoplasticity.

The Zy-4 specimen has been deformed by creep at $400{ }^{\circ} \mathrm{C}$ under a uniaxial stress of $127 \mathrm{MPa}$ during $200 \mathrm{~h}$, leading to a macroscopic axial strain of about 5\% (Fig. ??b), and finally cooled down to room temperature.

Neutron diffraction measurements were performed on a sample gage volume of about $5 \times 5 \times$ $10 \mathrm{~mm}^{3}$. The (0002) diffraction planes were chosen because their low multiplicity in the hcp cell gives rise to significant line shifts, and diffraction angles are in the range of the best resolution of the diffractometer. The relative accuracy on the average deformation over the diffracting volume $<\varepsilon_{\mathrm{g}}>\Omega \mathrm{g}$ is estimated to be about $1.10^{-4}$. The obtained results are shown in Fig. ??, where the angles $\phi$ and $\chi$ define the orientation of g (Fig. ??a). Experimental and predicted average strains $\left\langle\varepsilon_{g}\right\rangle_{\Omega \mathrm{g}}$ are in excellent agreement. Both the shape and the amplitude of the fluctuation with $\Omega_{\mathrm{g}}$ of the residual strain are very well captured by the model, meaning that the adopted affine linearization procedure accurately predicts the interphase interactions for the present material. 

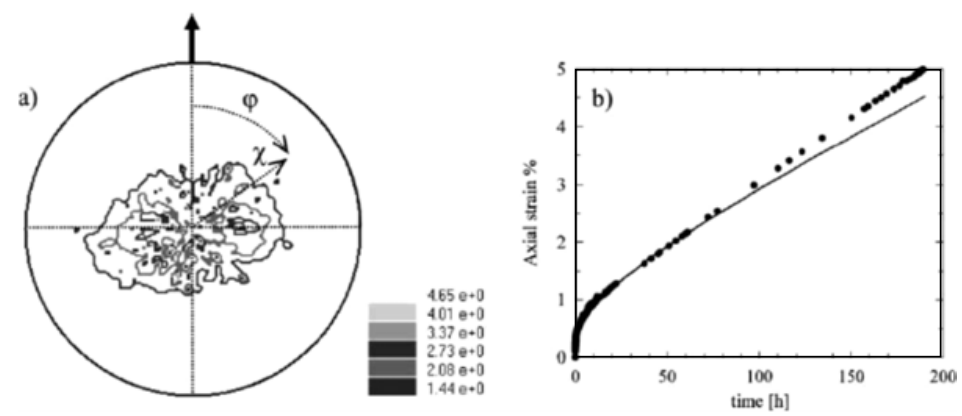

Figure 24. (a) (0002) pole figure measured by neutron diffraction. The arrow indicates the tensile direction under creep loading, and the angles $\chi$ and $\varphi$ define the orientation of g. (b) Experimental effective behaviour (dots), compared to the simulated one (line).



Figure 25. Fluctuation of $\left\langle\varepsilon_{\mathrm{g}}\right\rangle_{\Omega \mathrm{g}}$ with the orientation of $\mathrm{g}$ for (0002) diffracting planes, measured (dots) and simulated (lines).

At $\chi=\varphi=90^{\circ}$, the diffracting volume $\Omega_{g}$ consists on phases essentially tensiled perpendicular to their $<\mathrm{c}>$ axes, that is for which prismatic slip systems can be easily activated. These phases are found to retain a very small residual strain level. However, at $\chi=90^{\circ}$, and $\phi=0^{\circ}$, diffracting phases are mainly tensiled along the $<\mathrm{c}>$ axes, so that harder slip systems have to be activated with a higher level of subsequent residual strain. It is interesting to remark that the saturating level of $\left\langle\varepsilon_{\mathrm{g}}\right\rangle_{\Omega \mathrm{g}}$ obtained in that direction is consistent with the reference shear stress for pyramidal slip.

Neutron scattering thus provides statistical data concerning the volume distribution of residual strain. We have shown that these data can be compared rigorously to the results of homogenization schemes, and therefore they may be used for a reliable determination of the local constitutive relation.

\subsubsection{Stress determination after accidental conditions for $\mathrm{Zr}$ based alloys of PWR}

During the second stage of Loss Of Coolant Accident (LOCA) in Pressurized Water Reactors (PWR) zirconium-based fuel claddings undergo a high temperature oxidation (up to $1200^{\circ} \mathrm{C}$ ), then a water 


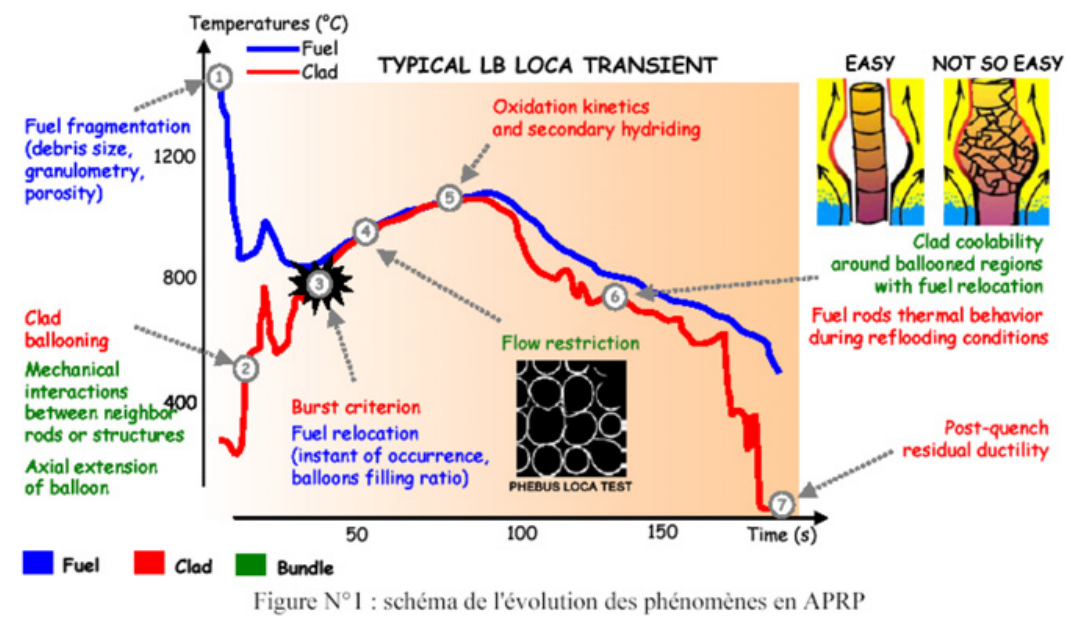

Figure 26. Evolution of the different phases during a LOCA.

quench (Fig. ??). After a single-side steam oxidation followed by a direct quench, the cladding is composed of three layers: an oxide (Zirconia) outer layer (formed at High Temperature, HT), always brittle at Room Temperature (RT), an intermediate oxygen stabilized alpha layer, always brittle at RT, called alpha(O), and an inner "prior-beta" layer, which is the only layer able to keep some significant Post Quench (PQ) ductility at RT. However, hydrogen absorbed because of service exposure or during the LOCA transient, concentrates in this layer and may leads to its embrittlement [14].

A. Cabrera Salcedo PhD work [15] proposes an original fracture scenario for a stratified Post Quench cladding tested by Ring Compression Tests (RCT), and its associated Finite Element model. PQ thermal stresses resulting from water quench of HT oxidized cladding are investigated, as well as progressive damage of three layers during an RCT.

In that way, residual stresses developed especially in the brittle intermediate layer with a high level of oxygen is of main interest if one is interested on mechanical behaviour of the PQ cladding tube. FE calculations taking into account thermal stresses appearing during the cooling down have shown the strong influence of various parameters, depending on the properties of the three layers, especially the intermediate one. In order to precise theses parameters a good solution is to have access to experimental data. That is why stress analyses have been performed on flat Zy-4 sample oxidized at high temperature $\left(1250^{\circ} \mathrm{C}\right.$ during 3250 s then quenched in air) (Fig. ??).

To determine the stress state in the intermediate layer it was needed to go through the oxide layer, and to make an average determination of stress value in the intermediate layer showing very large $\alpha(0)$ grains size (sometimes around few $\mathrm{mm}$ ). For that purpose, ND can be an excellent solution. Analyses were performed at LLB-Orphée at G5.2 spectrometer for a specific sample (intermediate layer thickness: $0.38 \mathrm{~mm}$ ) prepared for this very challenging experiment. In fact the gage volume is $0.5 \times 0.5 \times 20 \mathrm{~mm}^{3}$, which is not obvious for ND analyses!

XRD pattern is given Fig. ?? where diffraction peaks related to the three layers can be found.

We selected the $\alpha(0)$ layer and especially (10-11) plane at $2 \theta=70.3^{\circ}$ to determine stress in this intermediate layer. A schematic view for the orientation of the sample during the measurement is given Fig. ??a. Before the analyses, variation of $\Psi$ angle was performed with different location along the axis $\mathrm{X} 3$ in order to find the best conditions for analysing only the intermediate layer with maximum intensity for the (10-11) plane (Fig. ??b).

Then, 4 angles $\Psi$ were selected in order to determine the stress average value in the layer using well known $\sin ^{2} \Psi$ method. Diffraction peaks obtained in that case are given Fig. ??. One can see that stress is 
EPJ Web of Conferences

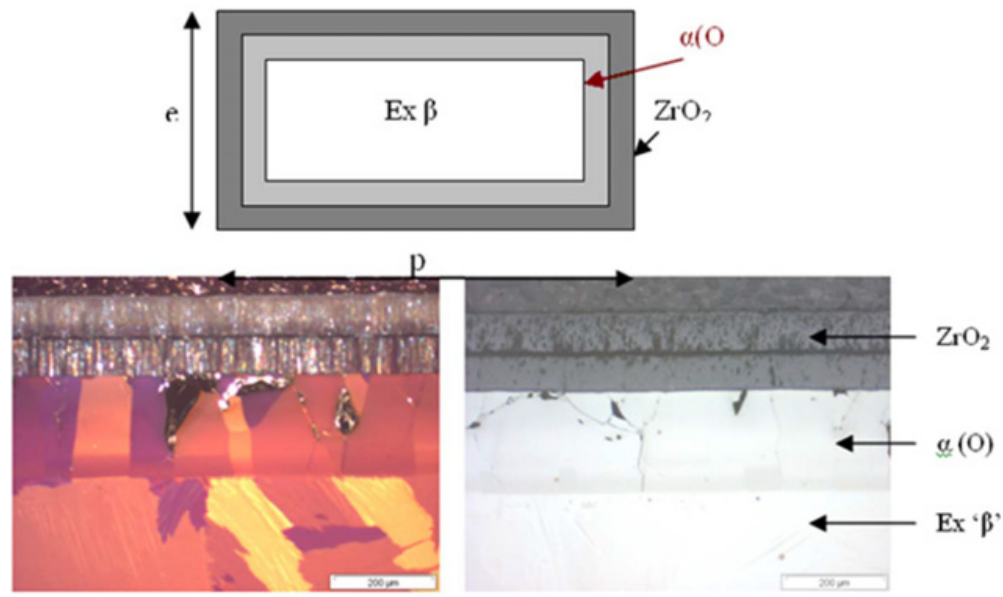

Figure 27. Specific sample prepared and microstructure obtained with the 3 different layers.

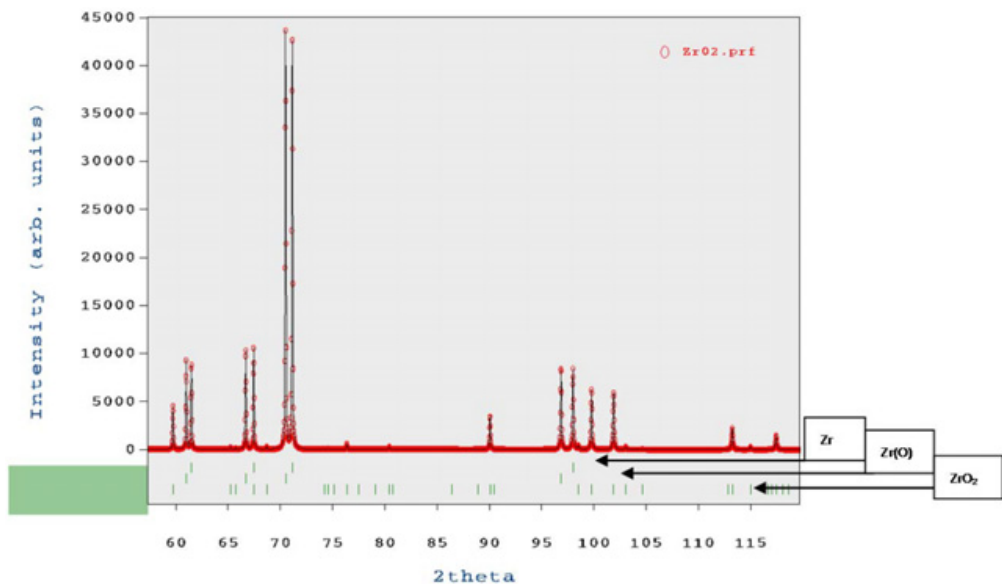

Figure 28. Neutron diffraction pattern obtained for the Zy-4 sample oxidized at high temperature.

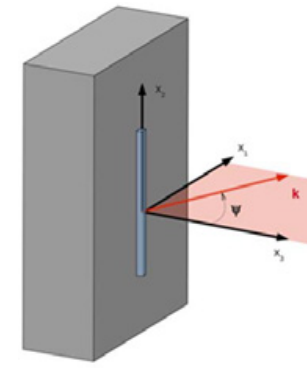

(a)

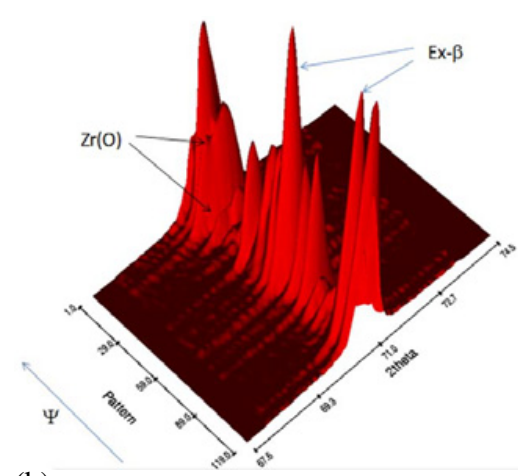

(b)

Figure 29. Schematic view of the orientation of the sample and diffraction vector (a) and 3D diffraction patterns obtained for different $\Psi$ angle (b). 


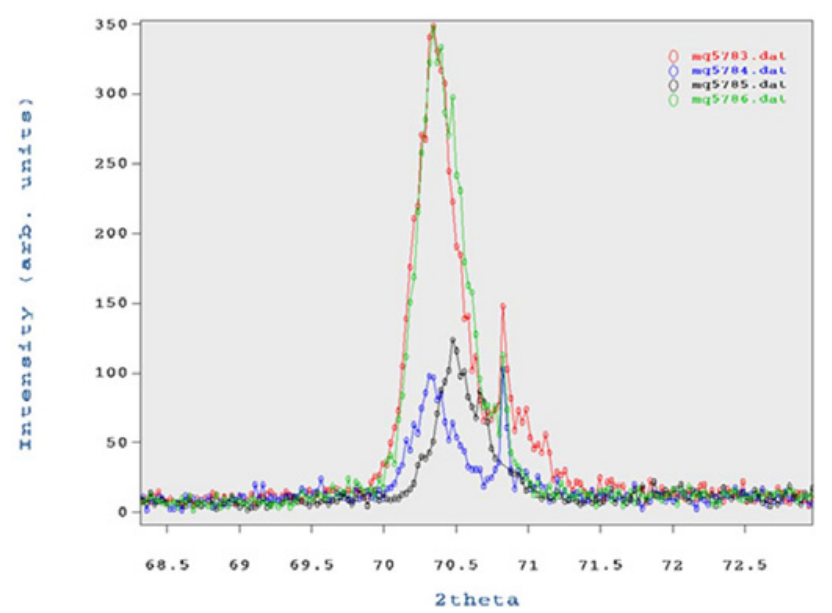

Figure 30. Diffraction pattern obtained in $\operatorname{Zr}(0)$ layer, plane (10.1), for $4 \Psi$ angles chosen.

in tension. With a very simplified analysis we determine the stress level after extrapolation at $\sin ^{2} \Psi=1$ leading to the deformation $\varepsilon 11=0.0009$. With the hypothesis of biaxial stress state, Young modulus of $71 \mathrm{GPa}$ and Poisson ration of 0.37 (values obtained from self-consistent calculation for (10.1) plane with isotropic texture), the stress value $\sigma 11$ is equal to $100 \mathrm{MPa}$ in tension.

Thanks to ND it has been possible to analyse the stress state in the $\alpha(0)$ layer, providing experimental values, comparable with Finite Element calculations. Nevertheless, to confirm this first results, improvement in the experimental analysis have to be done: other diffracting orientations have to be examined (using diffractometer with Euler circle) depending on the $\alpha(0)$ very coarse grains analysed in that specific composite sample formed of three layers.

\subsubsection{SANS analyses on Zr based alloys of PWR before and after irradiation}

The current challenge in the nuclear energy industry is to increase PWR fuel performance at burnups beyond $65 \mathrm{GWd} / \mathrm{t}$ in a more demanding operating environment. In this scope, a program was lunched to develop superior cladding and guide-tube materials. New zirconium alloys have been produced by AREVA and its industrial partners: quaternary materials ( $\mathrm{Zr}, \mathrm{Sn}, \mathrm{Fe}$ and $\mathrm{V}),(\mathrm{Zr}, \mathrm{Sn}, \mathrm{Fe}$ and $\mathrm{Nb}$ ), and ternary materials $(\mathrm{Zr}, \mathrm{Nb}$ and $\mathrm{O}$ ). The performances of these advanced alloys have been assessed in test loops (corrosion) and experimental reactors (growth, creep, hardening, etc.). For AREVA's fuel assemblies, the alloy referenced as $\operatorname{M}^{\mathrm{TM}}(\mathrm{Zr}-1 \% \mathrm{Nb}, \mathrm{O})$ in the recrystallized condition (RXA) replaces the stress-relieved (SRA) optimized low tin Zy-4 as a cladding material. This advanced alloy has been used in a wide range of PWR environments at burnups up to $78 \mathrm{GWd} / \mathrm{t}$ ( 7 annual cycles) and has demonstrated excellent in-reactor behaviour [16]. Previous works on Zr-alloys have already shown microstructural evolution of these materials under irradiation and the strong influence of this evolution on corrosion and irradiation growth [17]. Radiation-induced amorphization, dissolution, or reprecipitation phenomena especially affect $\mathrm{Zr}$ alloy properties. In that context, relevant microstructural observations are needed to increase our knowledge on the stability of the alloy under irradiation and to anticipate their in-reactor behaviour up to high burn-up.

Microstructural stability of the M5TMalloy under irradiation is usually investigated by Analytical Transmission Electron Microscopy (ATEM). In this study [18], Small Angle Neutron Scattering (SANS) has been performed on M5 (and also on RXA Zy-4 as a $0 \% \mathrm{Nb}$ standard) to provided quantitative and statistical information on the radiation-enhanced precipitation of $\beta$ - $\mathrm{Nb}$ needles. SANS technique is in 
Table 1. Irradiation conditions.

\begin{tabular}{ccc}
\hline Alloy & sample & Fluence. $10^{25} \mathrm{n} / \mathrm{m}^{2}(\mathrm{E}>1 \mathrm{MeV})$ \\
\hline RXA Zy-4 & $52 \mathrm{~N}$ & 2.97 \\
& $51 \mathrm{~N}$ & 6.22 \\
M5 $^{\mathrm{TM}}$ & $2 \mathrm{~N}$ & 2.97 \\
& $1 \mathrm{C}$ & 5.86 \\
\hline
\end{tabular}

some specific cases more powerful than Transmission Electron Microscopy for studying precipitation at the nanometer scale when the particles are very small $(\varphi \sim 5 \mathrm{~nm})$. In addition, SANS examines a much larger volume of material than TEM and brings more accurate values on particles size and density, at least with regard to averaged information. The aim of this complementary work using SANS was therefore to study the evolution of microstructure in $\mathrm{Zr}$ alloys and especially M5TMafter neutron irradiation, focusing on the $\beta$ - $\mathrm{Nb}$ precipitation, and to define the microstructure evolution after irradiation for two fluences.

The materials studied using the SANS technique were irradiated in the OSIRIS reactor (CEA/Saclay) at an average temperature of $310^{\circ} \mathrm{C}$ in the "Coralline" loop (155 b, PWR chemistry). In order to compare these samples with those observed by TEM, we can consider the irradiation doses for $52 \mathrm{~N}$ and $2 \mathrm{~N}$ samples equivalent to $\sim 1.5 \mathrm{PWR}$ cycle and the doses for $51 \mathrm{~N}$ and $1 \mathrm{C}$ samples equivalent to $\sim 3 \mathrm{PWR}$ cycles (Table ??).

The neutron scattering experiments were carried out at LLB-Orphée using the PAXY small-angle instrument. The wavelength $\lambda$ was $0.55 \mathrm{~nm}$ and the sample-to-detector distance (D) was $2 \mathrm{~m}$, covering a scattering vector $(\mathrm{q})$ range from $0.3-1.6 \mathrm{~nm}-1(\mathrm{q}=4 \pi \sin \theta / \lambda$, where $2 \theta$ is the scattering angle). Measurements were performed at room temperature.

The samples for the SANS experiments, cut, prepared, and conditioned in the hot cells of CEA/Saclay, were in the form of platelets of $5 \times 5 \times 0.4 \mathrm{~mm}^{3}$. Long experiment times $(5-10 \mathrm{~h})$ were necessary to reduce statistical errors (due to the small volume of material involved in the SANS experiments and also due to the small difference between the scattering length densities for $\mathrm{Nb}$ and $\mathrm{Zr}$ ).

The intensity scattered by an unirradiated reference specimen (either M5 ${ }^{\mathrm{TM}}$ or RXA-Zy-4) was subtracted to the intensities scattered by the irradiated samples in order to eliminate the incoherent scattering and the contributions of the matrix such as free surfaces, grain boundaries, and dislocations. For irradiated samples, hydrogen contribution due to the PWR environment also was taken into account depending on the irradiation dose and alloy.

We have plotted (Fig. ??a) the scattered intensity as a function of q for M5 $5^{\mathrm{TM}}$ (sample $2 \mathrm{~N}, \sim 1.5 \mathrm{PWR}$ cycle: fluence $2.97 \times 10^{25} \mathrm{n} / \mathrm{m}^{2}$ ). The shape difference of the scattered intensity obtained on unirradiated and irradiated samples can be explained (Fig. ??d) by two contributions; the first one at low angles is due to "large" particles, and the second one at high angles is due to small particles. On the basis of TEM observation on samples irradiated between 1 and 2 cycles (Fig. ??), we made the assumption that the particles are roughly spherical, and thus we estimated the size (diameter of particles) and density values (Fig. ??d): $\sim 2 \mathrm{~nm}$ for the smallest and $\sim 10 \mathrm{~nm}$ for the largest.

A quantitative analysis of the scattered intensity has been performed on the basis of two hypotheses:

-Nature of the $2 \mathrm{~nm}$ objects: If these objects were $\beta$-Nb particles, the deconvolution of the scattered intensity using this hypothesis would indicate a volume fraction of $\mathrm{Nb}$ higher than $1 \%$. Even though a partial $\mathrm{Nb}$ contribution cannot be excluded, this population has to be mainly attributed to defects clusters such as small loops, black dots, etc., with a number density of $10^{23} \mathrm{~m}^{-3}$.

-Nature of the $10 \mathrm{~nm}$ particles: if we consider all of these objects as $\beta$-Nb particles, the deconvolution of the scattered intensity leads to a volume fraction of particles in the range of $0.3 \%$ with a number density of $\sim 10^{22} \mathrm{~m}^{-3}$. However, in Zy-4 (52N sample), similar objects can be detected around $\sim 10 \mathrm{~nm}$ in size, but with a volume fraction at least ten times lower than in M5 ${ }^{\mathrm{TM}}$. In this alloy, where no $\beta-\mathrm{Nb}$ particles can be found, these objects are similar in size and density to $\langle\mathrm{a}\rangle$ loops already observed in RXA 


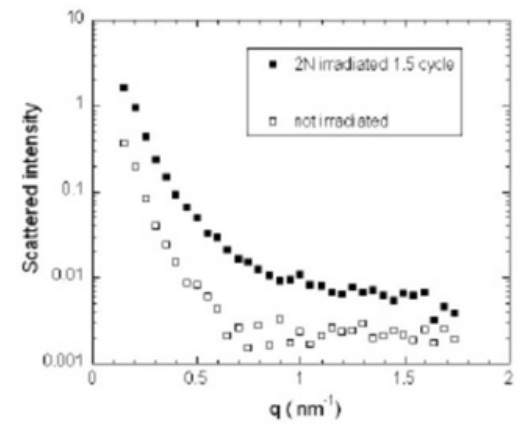

a)

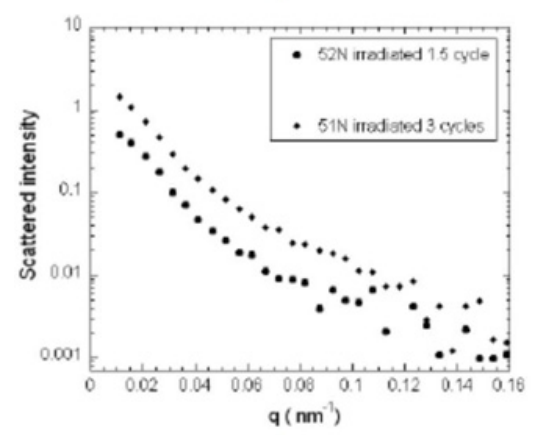

c)

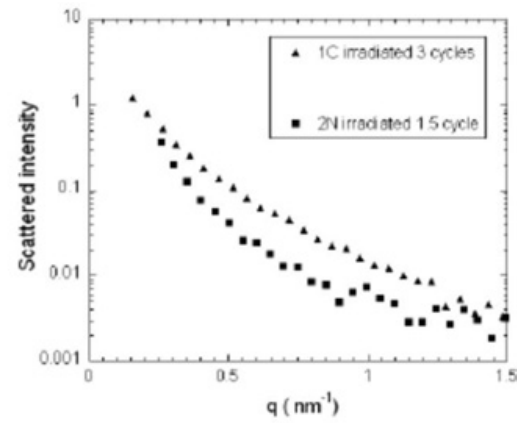

b)

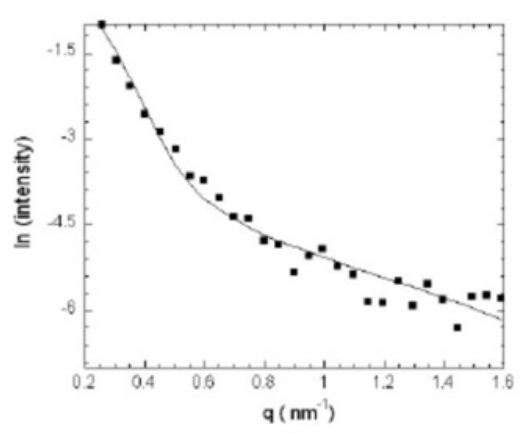

d)

Figure 31. SANS analysis performed on $\mathrm{Zr}$ alloys after irradiation: evolution of the scattered intensity as a function of $\mathrm{q}$ for a) M5 $5^{\mathrm{TM}}$ as-received and after $\sim 1.5$ PWR cycle, b) M5TM, and c) RXA Zy-4 after $\sim 1.5$ and $\sim 3$ PWR cycles, d) determination of the particle size for M5TM after $\sim 1.5$ PWR cycle.

Zy-4 by TEM with quite similar irradiation conditions [19] and thus are supposed to be dislocation loops. Consequently, the scattered intensity at low q in M5 ${ }^{\mathrm{TM}}$ seems result from two contributions: $\langle\mathrm{a}\rangle$ loops and radiation-induced precipitates. In order to quantify precipitation, the contribution of $\langle a\rangle$ loops has been subtracted in the M5 ${ }^{\mathrm{TM}}$ alloy taking into account SANS analyses performed on Zy-4 samples. Finally, using this "strong" hypothesis, and assuming a mean form factor for the kind of contribution, we obtained a volume fraction of $\sim 10 \mathrm{~nm} \beta$-Nb particles in the range of $0.2 \%$ with a $\sim 510^{21} \mathrm{~m}^{-3}$ density.

Therefore, although TEM and SANS were not carried out on the same specimens, it must be concluded that the results obtained with SANS are in good agreement with TEM for 1-2 cycle irradiated samples. The SANS technique gives additional accurate quantitative results on very small objects $(\sim 2 \mathrm{~nm})$ and on $\beta$ - $\mathrm{Nb}$ radiation-enhanced precipitation. Especially, $\beta$-Nb radiation-enhanced precipitation leads to a decrease in the niobium content in the matrix as early as after $\sim 1.5 \mathrm{PWR}$ cycle; SANS experiments give a larger $\beta$-Nb particle size $(\sim 10 \mathrm{~nm}$ versus $3-5 \mathrm{~nm})$ and a higher volume fraction than that measured by TEM. The number densities, however, are directly comparable. One can attribute size overestimations using SANS to successive data treatment essential to eliminating different contributions (non-irradiated material scattered intensity, $\langle\mathrm{a}\rangle$ loops). Sample $1 \mathrm{C}$ shows that there is an increase in the radiation-enhanced $\beta$-Nb precipitation after an irradiation dose of $5.86 \times 10^{25} \mathrm{n} / \mathrm{m}^{2} \sim$ 3 PWR cycles. With the same assumptions as before (sample $2 \mathrm{~N}$ ) and after deconvolution from Zy-4 (in that case $51 \mathrm{~N}$ sample), a volume fraction of particles in the range of $0.8 \%$ with a $\sim 2.510^{22} \mathrm{~m}^{-3}$ particle density is obtained. The absolute value has to be taken carefully, mainly with a qualitative aspect. Nevertheless, it shows a significant increase in the radiation-enhanced $\beta$-Nb precipitation with 


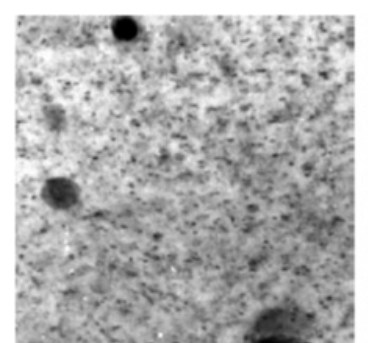

a)

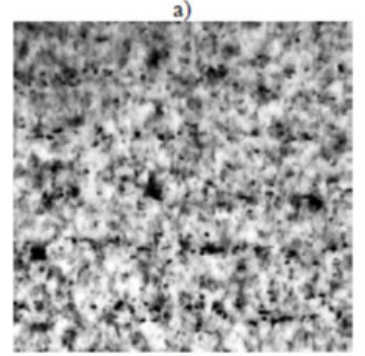

d)

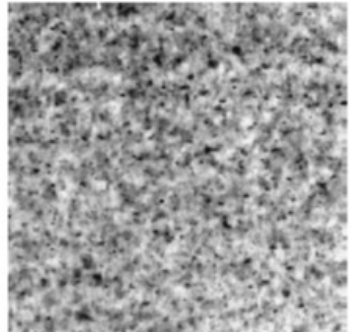

b)

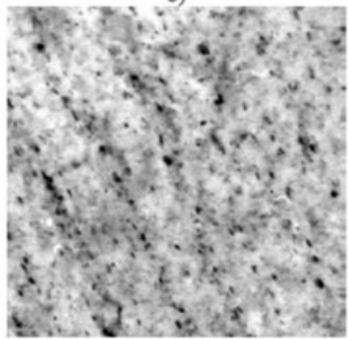

e)

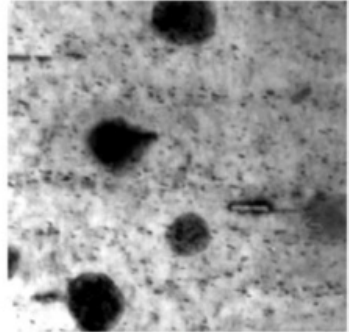

c)

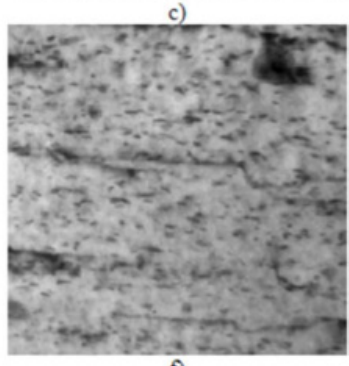

f)

$100 \mathrm{~nm}$

Figure 32. Micrographs of needle-like radiation-enhanced precipitation: a) $\mathrm{M}^{\mathrm{TM}} 2.1 \times 10^{25} \mathrm{n} / \mathrm{m}^{2}$, b) $\mathrm{Zr}-1 \% \mathrm{NbO}$ $2.8 \times 10^{25} \mathrm{n} / \mathrm{m}^{2}$, c) M5TM $3.6 \times 10^{25} \mathrm{n} / \mathrm{m}^{2}$, d) $\mathrm{Zr}-1 \% \mathrm{NbO} 5.7 \times 10^{25} \mathrm{n} / \mathrm{m}^{2}$, e) $\mathrm{Zr}-1 \% \mathrm{NbO} 8.2 \times 10^{25} \mathrm{n} / \mathrm{m}^{2}$, f) M5 ${ }^{\text {TM}} 13.1 \times 10^{25} \mathrm{n} / \mathrm{m}^{2}$.

irradiation dose. On the other hand, a strong evolution concerning the particle shape has been highlighted with SANS: the assumption of spherical particles is not valid after three cycles, and this is taken into account using an ellipsoid. The best fit on experimental data is obtained for a length/width ratio in the range of 2-3, which is quite consistent with TEM observations (Fig. ??b).

At least concerning the smallest particles, SANS analyses conducted on RXA Zy-4 samples bring a similar result as obtained for M5 ${ }^{\mathrm{TM}}$ : the evolution of the high angle scattered intensity is due to a $\sim 2 \mathrm{~nm}$ population of defect clusters, small loops, black dots, on the scattered intensity. For both materials, an increase of this population of around $2 \mathrm{~nm}$ particles with the fluence can be found (Fig. ??c), with for each case (1.5 and 3 PWR cycles) a higher volume fraction for M5TM (approximately twice the one obtained for Zy-4).

To conclude with the study of the radiation-induced particles with SANS, we can say that these particles are thermodynamically stable and are evidenced from the first cycle. Their density (about $1 \times 10^{22} \mathrm{~m}^{-3}$ ) seems to keep rising between 1.5 and 3 PWR cycles with a corresponding increase in volume fraction (Fig. ??). The particle shape is observed to change between 1.5 and 3 PWR cycles from spherical to probably ellipsoidal at roughly constant volume. SANS gives obviously an overestimated value of the volume fraction of these particles due to the critical and numerous deconvolutions used, whereas from TEM, accurate quantification is impossible because of the drastic dependence of volume fraction versus radius in such small particles. However, this intensive precipitation leads to a noticeable decrease of niobium content in the matrix (probably in the range of $0.1 \%$ at 1 PWR cycle).

\subsubsection{Texture analyses for ODS steels for SFR during the fabrication process}

Advances in powder metallurgy, like mechanical alloying process, have enabled the production of oxide dispersion strengthened (ODS) ferritic alloys from powders with uniform distributions of oxide particles within the ferritic matrix. One of the most interesting effects of the fine particles homogeneously 

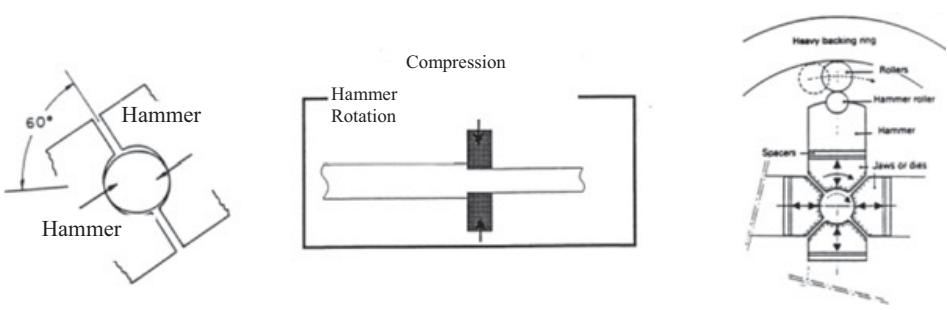

Figure 33. Schematic sketch of the swaging process.

distributed in the matrix, is the enhancement of the strength values of the ODS ferritic materials compared to the conventional ferritic alloys, especially in the range of high temperatures [20]. These kinds of materials present a high stability of their microstructures associated to the high temperatures of recrystallization [21] and also high resistance to environmental degradation [22]. These attractive properties make the ODS ferritic alloys the promising candidates for high temperature application materials, in particular for long-life fuel cladding of sodium cooled fast reactors.

Nevertheless, to obtain the desired properties of the final products, it is very important to control the evolution of metallurgical and mechanical characteristics with heat treatments and working processes performed during the fabrication route. In particular, recrystallization of these materials after cold working process can lead to "abnormal" grain growth, which is very often linked to a particular crystallographic preferred orientation of the grain [23]. This point is the main goal of this study which investigates the evolution of the texture of MA957 alloy, deformed by swaging with different coldworking levels and then recrystallized.

Due to the strong heterogeneity of the texture and microstructure, we have performed in this study texture analysis [24] at three different scales: using X-ray diffraction techniques after deformation (which gives surface information up to a depth of $\sim 10$ micron), using neutron facility both after deformation and recrystallization (which gives a volumic analysis $\sim 1 \mathrm{~cm}^{3}$ ) and Electron Back Scattered Diffraction (EBSD) analysis, to have local information at the level of one grain $\sim 1$ micron.

The commercial MA 957 alloy analysed here has the following nominal compositions (in wt \%): Fe-14Cr-0.3Mo-1Ti with oxide particles volume fraction $\mathrm{Y}_{2} \mathrm{O}_{3}=0.5 \%$. This alloy has been supplied as extruded rods of $25 \mathrm{~mm}$ diameter and an additional hot extrusion has been performed in order to obtain rods of about $11 \mathrm{~mm}$ diameter. From this starting geometry, rods were subsequently swaged to attain up to $60 \%$ Cold-Work (CW) level by cumulative passes (Fig. ??). Each pass was calculated to result in $10 \%$ area section reduction. In this work we only studied 30 and $60 \%$ area section reduction. After the deformation process, isochronal heat treatments in the temperature range from 950 to $1470{ }^{\circ} \mathrm{C}$ during one to two hours have been performed. In this paper we focus on the $1470{ }^{\circ} \mathrm{C}$ heat treatment lasting 2 hours.

A very fine microstructure is obtained after swaging up to $60 \%$, which is not observable by optical metallography, nor Scanning Electron Microscopy (SEM) (Fig. ??a). Using TEM we observe grains with strong anisotropic shape, elongated along the axial direction of the rod with a mean diameter of $500 \mathrm{~nm}$ and a grain aspect ratio (length/diameter) of 10. After recrystallization, an abnormal grain growth or secondary recrystallization is obtained giving rise to a coarse grained structure located at different regions along the radial direction of the rod. This strong heterogeneity depends also on the cold work level for a given heat treatment temperature: for the $30 \% \mathrm{CW}$, the heart and periphery of the rod show coarse grains whereas the intermediate zone has a very fine structure $(\sim 10 \mu \mathrm{m})$. For the $60 \%$ $\mathrm{CW}$ this fine grain size is nearly found for every points of the section, and we can see less heterogeneity, except from the periphery where nearly millimetric grains can be observed (Fig. ??b). 


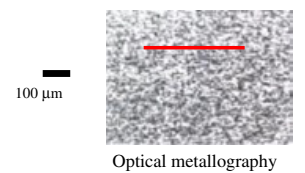

(a)

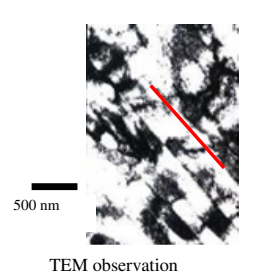

TEM observation

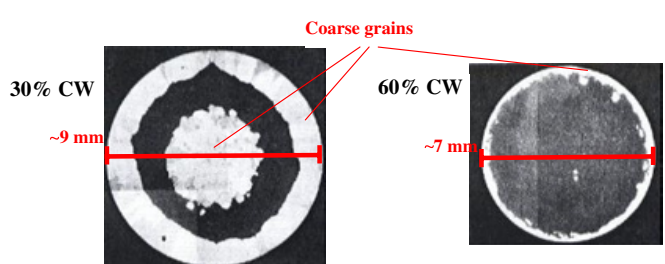

(b)

Figure 34. Microstructure after $60 \%$ area section reduction from TEM analyses (red arrows give the axial direction of the rod) (a), microstructure after recrystallization (optical metallography) (b).
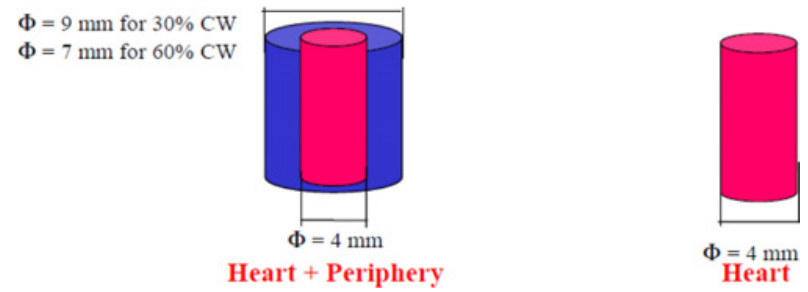

Figure 35. Specific sample preparation for neutron diffraction analysis.

The volumic texture analysis was performed using ND technique. One of its specificities is to measure complete pole figures in transmission mode whereas conventional XRD pole figures are unreliable for high tilt angles $(\chi)$. Other advantages are that no surface preparation is required for the sample and that the analysis is performed for a volume which can be up to $1 \mathrm{~cm}^{3}$ in comparison with conventional XRD method dealing with a small penetration depth. The experiments were performed at LLB-Orphée, on the four-circle diffractometer -6T1- dedicated to pole figure determination. The neutron wavelength was $1.159 \AA$, selected by a $\mathrm{Cu}$ (111) monochromator. The pole figures which were established were $\{110\},\{002\}$ and $\{211\}$. No absorption correction was applied. A specific sample preparation, Fig. ??, was performed to avoid the heterogeneity problems: different diameters were machined for the 30 and $60 \%$ cold-worked specimens before and after recrystallization to analyse separately the heart and the periphery of the rod (2 types of sample: heart + periphery, heart).

Whatever the deformation, for both methods, XRD and ND diffraction (see only the results for ND Fig. ??a), a strong $\alpha$-fibre texture is observed: [110] // rod axis direction with no gradient along the radial direction is found, but a reinforcement of this texture with the cold work level is obtained. The Bunge's J texture index [10], which accounts for the sharpness of the overall texture, (for a random sample the $\mathbf{J}$ index and (hkl) intensity are equal to 1 ), is respectively equal to 26 and 35 for 30 and $60 \% \mathrm{CW}$ specimens.

After recrystallization, only ND texture analyses are representative of the real texture, especially for low cold work level. Using XRD, the overlapping of different types of texture at the surface of the rods coming from a heterogeneous distribution of textures along the radial direction of swaged samples, makes the analysis very difficult.

In the heart of the $30 \% \mathrm{CW}$ sample (Fig. ??b), we observe a new fibre texture related to the coarse grain structure, $\{111\}\langle u v w\rangle, \gamma$-fibre, when for the same location and $60 \% \mathrm{CW}$ we find again the $\alpha$ fibre texture linked to the fine homogeneous grained structure. But there is also the appearance of a strong $\{111\}\langle 3-1-2\rangle$ orientation probably due to isolated coarse grain in the heart of the sample (Fig. ??b). Considering the total rod texture analysis (heart + periphery), we observe in the case of $30 \%$ $\mathrm{CW}$ the appearance of the intermediate fine-grained structure with the already found $\alpha$-fibre. For the $60 \% \mathrm{CW}$, the periphery showing coarse grains has also, just like the $30 \% \mathrm{CW}$, a $\gamma-\{111\}<\mathrm{uvw}>$ fibre texture. 
JDN 21
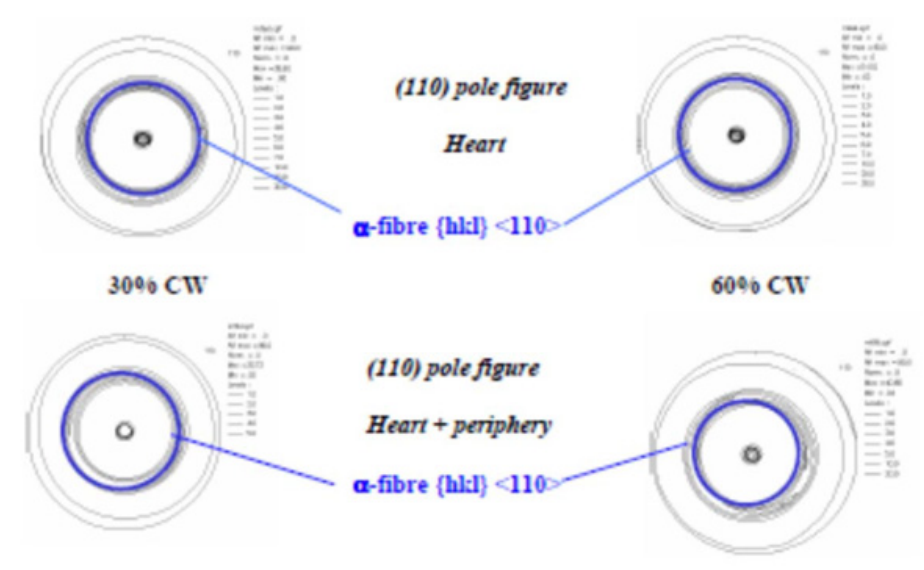

(a)

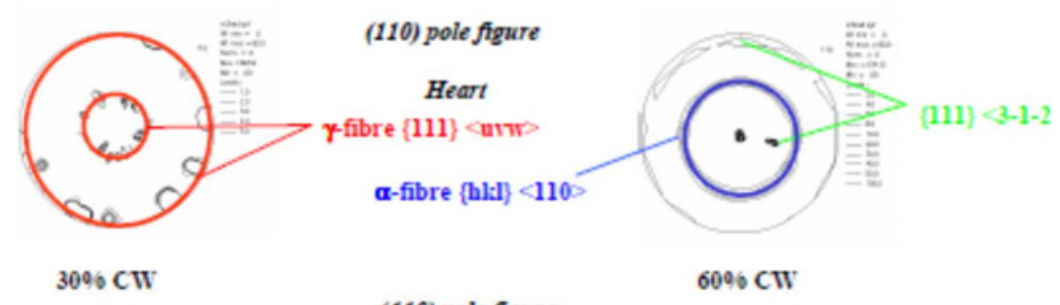

(b)

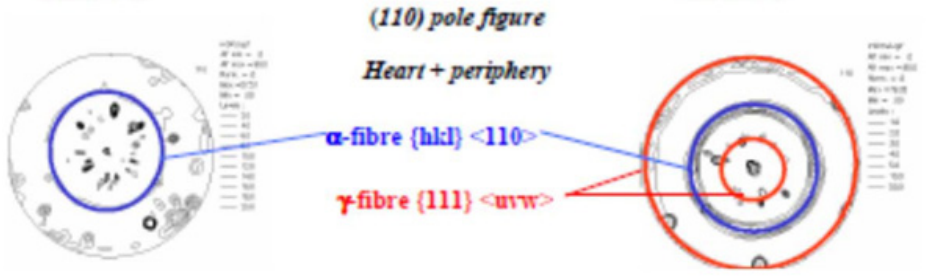

Figure 36. Texture analysis using neutron facility after deformation (a) and after recrystallization (b).

Thanks to neutron diffraction techniques, we were able to measure the texture in the coarse grain regions with a very good statistic. Only few orientations belonging to $\gamma$-fibre are visible in the isointensity pole figures of Fig. ??b. This is an effect of the coarse grains size. This heterogeneity appearing after recrystallization is probably related to a heterogeneous radial distribution of strains induced by cold-work into the rods, especially to the residual stress state found along the radial direction of the rod as discussed later: stored energy analysis are in progress to explicit at the local scale these behaviour in order to furnish some input data for the simulation of static recrystallization

\subsubsection{SANS analyses of ODS steels for SFR along the fabrication route}

The development of next generation nuclear reactors requires the availability of structural materials with very high mechanical creep properties and excellent resistance to irradiation. In this context, Fe 9-14\% $\mathrm{Cr}$ steels strengthened by a fine dispersion of oxides $\mathrm{Y}_{2} \mathrm{Ti}_{2} \mathrm{O}_{7}$ are booming. These materials are obtained by powder metallurgy. One fabrication route is to produce alloyed powders by mechanical alloying and consolidate the material by hot extrusion or HIP (Hot Isostatic Pressing). The precipitation occurs during the hot consolidation step and evolves during subsequent annealing at high temperature. However, the tensile or creep behavior of ODS steels varies with the oxide distribution. With a view to understand the 

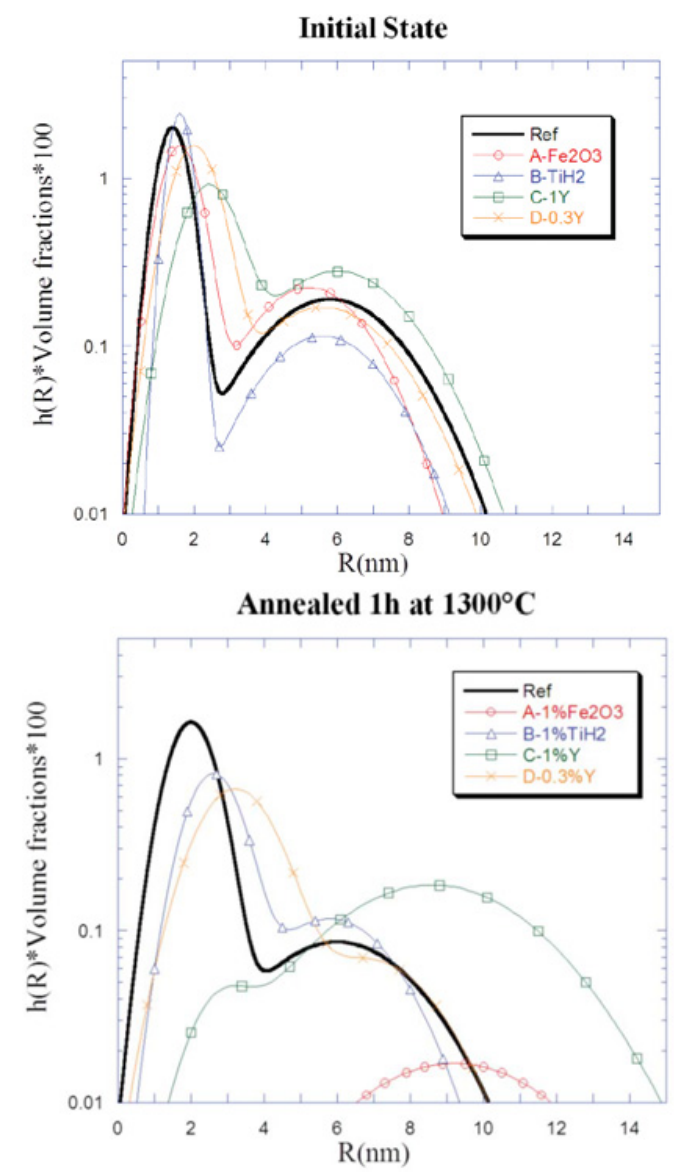

Figure 37. Oxides size distribution determined by SANS in the different alloys at the consolidated state then after annealing of $1 \mathrm{~h}$ at $1300^{\circ} \mathrm{C}$.

mechanisms of precipitation and the nanostructure evolution, the oxides precipitation coarsening was studied as a function of nominal content of $\mathrm{Y}, \mathrm{Ti}$ and $\mathrm{O}$ of the alloys using small-angle neutron scattering technique (SANS) and Transmission Electronic Microscopy (performed at CEA/SRMA) [25-27].

The effect of the fluctuation of the $\mathrm{Y}, \mathrm{Ti}$ and $\mathrm{O}$ contents around reference values, usually used, was analyzed with the dual objective of specifying the precipitation kinetics and the recrystallization conditions between $850{ }^{\circ} \mathrm{C}$ and $1450^{\circ} \mathrm{C}$. The reference material is a Fe-14Cr- $1 \mathrm{~W}-0,0-3 \mathrm{Ti}, 3 \mathrm{Y}_{2} \mathrm{O}_{3}$ ferritic steel, and 4 nuances were elaborated $\mathrm{A}-\mathrm{D}$, their basic chemical composition is the same as the reference sample with the addition of $1 \% \mathrm{Fe}_{2} \mathrm{O}_{3}$ for sample $\mathrm{A}, 1 \% \mathrm{TiH}_{2}$ for sample $\mathrm{B}, 1 \%$ Y for sample $\mathrm{C}$ and $0.3 \% \mathrm{Y}$ for sample D.

SANS results are presented Fig. ??. The size distribution of nanoparticles determined on all the samples at the consolidated state showed a similar behavior: a bimodal distribution was observed, with radius centered around $1.5 \mathrm{~nm}$ and at $6 \mathrm{~nm}$, respectively. Small variation are observable: the particles sizes are smallest in reference sample, Sample A with $1 \% \mathrm{Fe}_{2} \mathrm{O}_{3}$ and in Sample B with $1 \%$ of $\mathrm{TiH}_{2}$ (about $1.6 \mathrm{~nm}$ and $5.5 \mathrm{~nm}$ ), while they are largest in sample $\mathrm{C}$ with $1 \%$ of Yttrium $(2.4 \mathrm{~nm}, 6 \mathrm{~nm})$.

TEM observations have been performed. The microstructures of the alloys are similar and a very good agreement with SANS size distributions was found (see example given Fig. ??). 

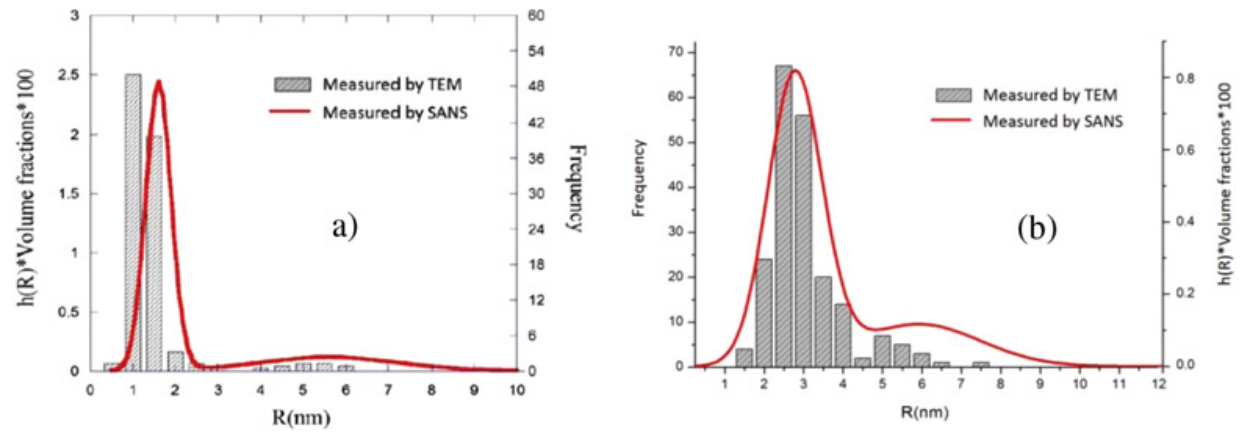

Figure 38. Comparison between the TEM histogram and the SANS distributions for sample B at the initial state (a) and annealed at $1300^{\circ} \mathrm{C}$ for 1 hour (b).

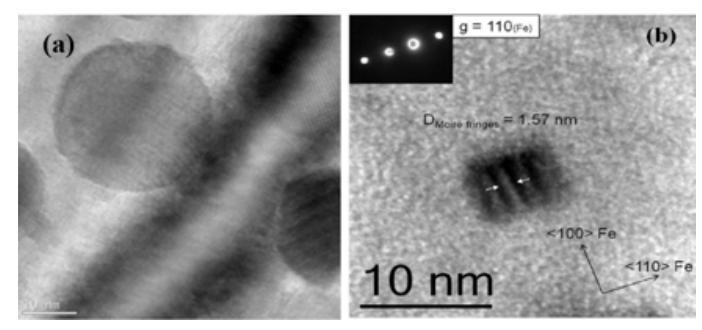

Figure 39. TEM observations after an annealing of $1 \mathrm{~h}$ at $1300^{\circ} \mathrm{C}$ on: (a) $\mathrm{Y}$ rich alloy; (b) Ti rich alloy.

On the other hand, after annealing at high temperature (between 1300 and $1450{ }^{\circ} \mathrm{C}$ ), we note a very wide disparity in the nanostructure and microstructure evolution. Firstly, the sizes and volume fraction of nanoparticles of the reference sample remain stable at $1300^{\circ} \mathrm{C}$ (Fig. ??b). A same behavior is observed for the sample $\mathrm{B}$ (with $1 \% \mathrm{TiH}_{2}$ ). Comparing with previous samples, the sample $\mathrm{D}$ with $0.3 \% \mathrm{Y}$ is less stable but the coarsening remains slow. In the Sample C with $1 \% \mathrm{Y}$ addition, the particle size increased significantly: the mean radius is around $8.5 \mathrm{~nm}$, which is more than twice the initial value. Finally, for the Sample A with $1 \% \mathrm{Fe}_{2} \mathrm{O}_{3}$ addition, SANS results show a huge decrease of the measured volume fraction (to $0.06 \%$ ) and the mean radius of particles reached about $9 \mathrm{~nm}$. So for this sample annealed at $1300{ }^{\circ} \mathrm{C}$ for 1 hour, the particle growth was the most significant. Therefore, the small size distribution has totally disappeared and, only some of the large particles remain observable in the q range available by SANS. Almost all the particles reached a size which is too large to be detected by this technique. The TEM investigations confirmed this result.

TEM investigations allowed getting complementary information to understand these differences of precipitation kinetics. First, in the reference simple, high resolution observations showed that the crystallographic structure is consistent with the expected Pyrochlore phase $\mathrm{Y}_{2} \mathrm{Ti}_{2} \mathrm{O}_{7}$. It was highlighted that the shape, size, and orientation relationship between the particles and the matrix are clearly dependent on the material. For alloys with a concentration ratio [Ti]/[Y] near or greater than 1, nanooxides are cubic (Fig. ??b) with coherent orientation relationship with the matrix (cube on cube ([100] oxides//[100] matrix).) The coarsening is so slow. In the yttrium rich alloy ([Ti]/[Y] $<1)$, the oxides are spherical (Fig. ??a), large and the orientation relationships are not or partially coherent with the matrix.

The difference of orientation relationship and chemical composition between precipitates and the matrix can explain the differences in behavior during annealing. The energy of oxide/matrix interface depends on the orientation relationships and increases with the disorientation. This parameter governing 
in part the coarsening kinetics, it could explains a part of the stability of oxides for alloys with $[\mathrm{Ti}] /[\mathrm{Y}] \geq 1$ even at high temperature $\left(1450^{\circ} \mathrm{C}\right)$. Contrary, in the $\mathrm{O}$ or $\mathrm{Y}$ rich alloys, there is a high energy of interface associated with the disorientation oxide/matrix and a fast coarsening of the particles. The recrystallization process is also affected. It was observed only in alloys exhibiting large oxides a recrystallization of the microstructure.

\section{References}

[1] A. Lodini, M. Perrin Analyse des contraintes résiduelles par diffraction des rayons X et des neutrons, Ed. CEA, ISBN 2-7272-0182-6, 1996.

[2] IAEA TECDOC 1457, Measurement of residual stress in materials using neutrons, June 2005.

[3] A. Lodini, T. Baudin, Rayonnement synchrotron, rayons X et neutrons au service des matériaux, Analyse des contraintes et textures, EDP Sciences 2012.

[4] M. Ceretti, Strain and stress analysis by neutron diffraction, ECNS03 Neutrons Stress Analysis Course, September 1-2, 2003.

[5] M E Fitzpatrick and A Lodini, Analysis of Residual Stress by Diffraction Using Neutron and Synchrotron Radiation, Meas. Sci. Technol. 14, 1739, 2003.

[6] I. C. Noyan and J. B. Cohen, Residual Stress, Measurement by Diffraction and Interpretation, Springer-Verlag, New York, 1987: A, pp. 101-102; B, pp. 125-6; C, pp. 157-159 and D, pp. 126-130.

[7] G. Kostorz, "Neutron Scattering", Academic Press New York (1979) 227

[8] M.H. Mathon and C.H. de Novion, J. Phys. IV France 9 (1999) 127-149

[9] M.H. Mathon et al., Journal of Nuclear Materials 312 (2003) 236-248

[10] M-H. Mathon, Y. de Carlan, X. Averty, A. Alamo, C.H. de Novion, Journal of ASTM International, October 2005, Vol. $2 \mathrm{~N}^{\circ}$, Paper ID JAI12381

[11] Castelnau O, Béchade J-L, Brenner R, Chauveau T, Bacroix B, et al. In: Miannay D, Costa P, Francçois D, Pineau A, editors. Advances in mechanical behaviour, plasticity and damage Proc EUROMAT 2000. France: Tours; 2000. p. 911-6.

[12] Crépin J, Bretheau T, Caldemaison D. Acta Metall Materé 1995;43(10):3709-19.

[13] N. Letouze, R. Brenner, O. Castelnau, J.-L. Béchade, and M. Mathon, "Residual strain distribution in Zircaloy-4 measured by neutron diffraction and estimated by homogenization techniques," Scripta Materialia, vol. 47, pp. 595-599, Nov. 12002.

[14] Brachet J.-C, Vandenberghe-Maillot V, Portier L, Gilbon D, Lesbros A, Waeckel N, Mardon J.-P. Hydrogen Content, Preoxidation, and Cooling Scenario Effects on Post-Quench Microstructure and Mechanical Properties of Zircaloy-4 and M5®Alloys in LOCA Conditions. Journal of ASTM International, May 2008, Vol 5, No5.

[15] A Cabrera Salcedo $\mathrm{PhD}$, Modélisation de la tenue à la trempe et du comportement mécanique post trempe des gaines de combustible de réacteurs à eau pressurisée, Ecole Nationale Supérieure des Mines de Paris, 2012.

[16] Mardon, J. P., Garner, G., Beslu, P., and Charquet, D., "Update on the Development of Advanced Zirconium Alloys for PWR Fuel Rod Claddings," ANS Portland, 2-6 March 1997, pp. 405-412.

[17] Gilbon, D., Soniak, A., Doriot, S., and Mardon, J. P., "Irradiation Creep and Growth Behaviour, and Microstructural Evolution of Advanced Zr-Base Alloys," Zirconium in the Nuclear Industry: Twelfth International Symposium, ASTM STP 1354, G. P. Sabol and G. D. Moan, Eds., ASTM International, West Conshohocken, PA, 2000, pp. 51-73.

[18] S. Doriot, D. Gilbon, J.-L. Béchade, M.-H. Mathon, L. Legras, and J.-P. Mardon, "Microstructural stability of M5 (TM) alloy irradiated up to high neutron fluences," in ZIRCONIUM IN THE NUCLEAR INDUSTRY: 14TH INTERNATIONAL SYMPOSIUM (Rudling, $P$ and Kammenzind, B, ed.), vol. 1467 of American Society for Testing and Materials Special Technical 


\section{JDN 21}

Publications, pp. 175-201, ASTM Int Comm B10, 2005. 14th International Symposium on Zirconium in the Nuclear Industry, Stockholm, Sweden, Jun. 13-17, 2004.

[19] Simonot, C., "Microstructural Evolution of Zirconium Alloys under Irradiation. Link with the Irradiation Growth Phenomenon," thesis of Paris XI University, Orsay, France, 1995, réf. CEA-R -5718 .

[20] I.C. Elliot, G.A.J. Hack, Proceedings of the ASM International Conference on Structural Applications of Mechanical Alloying, Myrtle Beach, South Carolina, 27-29 March 1990, p. 15.

[21] A. Alamo, H. Réglé, G. Pons, J.L. Béchade, Proceedings on the International Symposium on Mechanical Alloying, Kyoto, Japan, May 1991, Materials Science Forum 88-90 (1992), p. 183.

[22] J.J. Fischer, J.J. de Barbadillo, M.J. Shaw, Proceedings of the ASM International Conference on Structural Applications of Mechanical Alloying, Myrtle Beach, South Carolina, 27-29 march 1990, p.79.

[23] H. Réglé, PhD Université de Paris-Sud Orsay, 1994.

[24] J.-L. Béchade, M. Mathon, V. Branger, H. Regle, and A. Alamo, "Texture analysis of oxide dispersion strengthened (ODS) Fe alloys by X-ray and neutron diffraction," Journal de Physique IV, vol. 12, pp. 155-163, Jul 2002. X-Ray and Matter Conference (RX 2001), Strasbourg, France, Dec. 04-07, 2001.

[25] S.Y. Zhong et al., J. Nucl. Mat., 428 (2012) 154.

[26] J. Ribis, M.-L. Lescoat, S.Y. Zhong, M.-H. Mathon, Y. de Carlan, Journal of nuclear material Vol. 442, Issues 1-3, Supplement 1 (2013) pp. 101-105.

[27] S.Y. Zhong, J. Ribis, N. Lochet, Y. de Carlan, V. Klosek, M.H. Mathon, Journal of nuclear materials Volume 455 (2014) pp. 618-623. 